\title{
Article \\ Impact of Vertical Blender Unit Parameters on Subsequent Process Parameters and Tablet Properties in a Continuous Direct Compression Line
}

\author{
Marius J. Kreiser ${ }^{1,2} \mathbb{D}$, Christoph Wabel $^{1}$ and Karl G. Wagner ${ }^{2, *(\mathbb{D})}$ \\ 1 Product and Process Development, Pfizer Manufacturing Deutschland GmbH, 79108 Freiburg, Germany; \\ marius.kreiser@pfizer.com (M.J.K.); christoph.wabel@pfizer.com (C.W.) \\ 2 Department of Pharmaceutical Technology and Biopharmaceutics, University of Bonn, 53121 Bonn, Germany \\ * Correspondence: karl.wagner@uni-bonn.de
}

check for updates

Citation: Kreiser, M.J.; Wabel, C.; Wagner, K.G. Impact of Vertical Blender Unit Parameters on Subsequent Process Parameters and Tablet Properties in a Continuous Direct Compression Line. Pharmaceutics 2022, 14, 278. https://doi.org/10.3390/ pharmaceutics 14020278

Academic Editor: Colin Hare

Received: 9 December 2021

Accepted: 20 January 2022

Published: 25 January 2022

Publisher's Note: MDPI stays neutral with regard to jurisdictional claims in published maps and institutional affiliations.

Copyright: (c) 2022 by the authors. Licensee MDPI, Basel, Switzerland. This article is an open access article distributed under the terms and conditions of the Creative Commons Attribution (CC BY) license (https:// creativecommons.org/licenses/by/ $4.0 /)$.

\begin{abstract}
The continuous manufacturing of solid oral-dosage forms represents an emerging technology among the pharmaceutical industry, where several process steps are combined in one production line. As all mixture components, including the lubricant (magnesium stearate), are passing simultaneously through one blender, an impact on the subsequent process steps and critical product properties, such as content uniformity and tablet tensile strength, is to be expected. A design of experiment (DoE) was performed to investigate the impact of the blender variables hold-up mass (HUM), impeller speed (IMP) and throughput (THR) on the mixing step and the subsequent continuous manufacturing process steps. Significant impacts on the mixing parameters (exit valve opening width (EV), exit valve opening width standard deviation (EV SD), torque of lower impeller $\left(\mathrm{T}_{\mathrm{L}}\right)$, torque of lower impeller $\mathrm{SD}\left(\mathrm{T}_{\mathrm{L}} \mathrm{SD}\right), \mathrm{HUM} \mathrm{SD}$ and blend potency $\mathrm{SD}$ ), material attributes of the blend (conditioned bulk density (CBD), flow rate index (FRI) and particle size ( $\mathrm{d}_{10}$ values)), tableting parameters (fill depth (FD), bottom main compression height $(\mathrm{BCH})$ and ejection force $(\mathrm{EF})$ ) and tablet properties (tablet thickness (TT), tablet weight (TW) and tensile strength (TS)) could be found. Furthermore, relations between these process parameters were evaluated to define which process states were caused by which input variables. For example, the mixing parameters were mainly impacted by impeller speed, and material attributes, FD and TS were mainly influenced by variations in total blade passes (TBP). The current work presents a rational methodology to minimize process variability based on the main blender variables hold-up mass, impeller speed and throughput. Moreover, the results facilitated a knowledge-based optimization of the process parameters for optimum product properties.
\end{abstract}

Keywords: continuous manufacturing; continuous mixing technology; vertical blender; direct compression; lubrication; material characterization

\section{Introduction}

Continuous manufacturing lines are supplied by various vendors and distributed amongst the pharmaceutical industry. Next to the benefit of continuous manufacturing, the modular setup allows for an easier transfer amongst various production sites, as the setup can be more easily cloned from the pilot plant or launch site [1]. The PCMM (portable, continuous, modular and miniature) installed at the Pfizer site in Freiburg, Germany, consists of a GEA Compact Feeder, a vertical continuous blender (CMT-continuous mixing technology), a MODUL ${ }^{\mathrm{TM}} \mathrm{P}$ tablet press equipped with an NIR (near infrared) probe installed in the feed frame and an at-line combi-tester to analyze tablet properties, such as thickness, weight and crushing strength (Figure 1). 


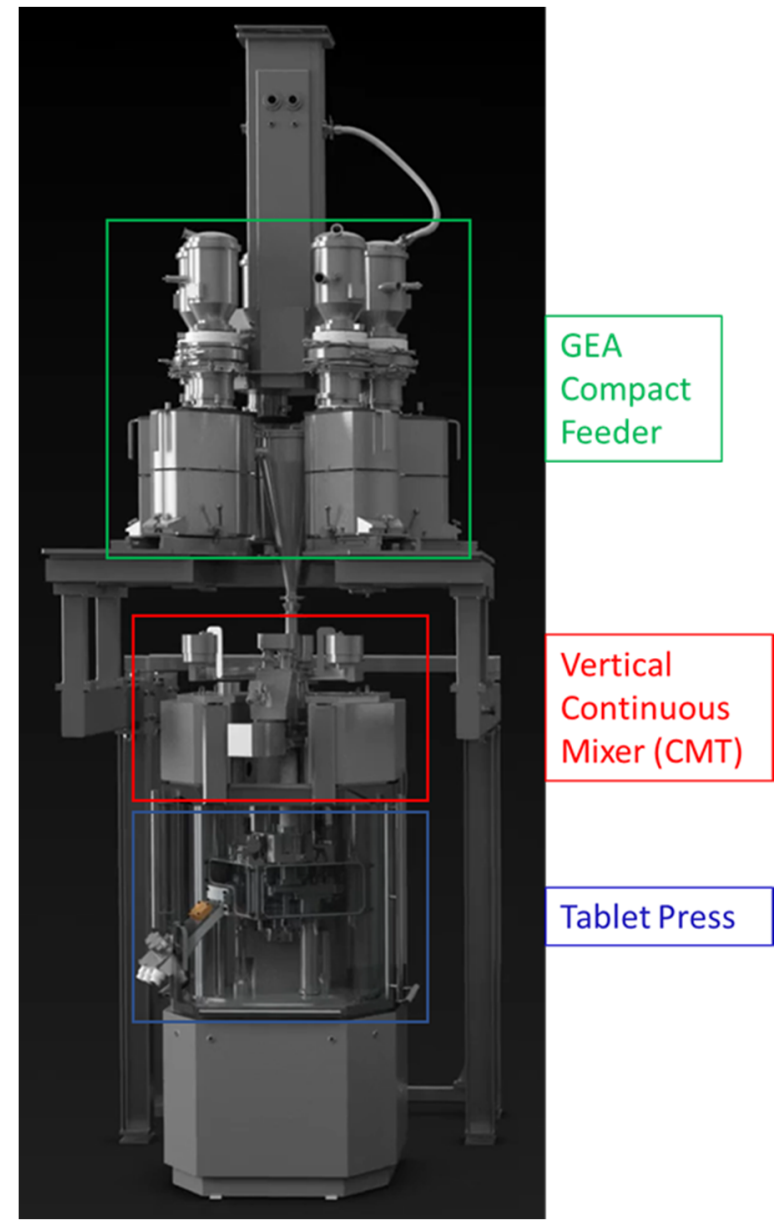

Figure 1. Overview of the direct compression line used for this trial.

Basically, for each raw material, the powder is transferred from a polyethylene bag via a top-up valve into an agitated hopper, where co-rotating screws supply the powder by the loss in weight $(\mathrm{LiW})$ principle at a composition related feed rate. The continuous process demands a periodical refill of the hopper triggered by a defined refill level, performed by a rotating volumetric refill device with flexible volume inserts $[2,3]$.

Since feeding is the first step within a continuous process, it is consequently one of the first critical control elements besides the material attributes. Accurate feeding is substantial for the quality of a continuous process to avoid deviations regarding the quality of blend and content uniformity of the tablets [4-8].

To provide low variability in feed rate, the optimal feeder design and the corresponding parameter settings, such as refill level, top-up volume, screw pitch, feed-factor array (governing dosing in volumetric mode during e.g., refill) and gearbox type (Figure 2), should be individually adjusted based on composition, throughput and powder attributes [3,4,7-13].

Several feeders supply each raw material separately, and the powder falls through the conical-shaped inlet hopper into the vertical continuous mixer. It is composed of two regions: the upper delumping region and the lower mixing region (Figure 3). In both, the impellers can be adjusted independently regarding speed, direction and vertical position, i.e., the gap between impeller and conical sieve. In the delumping region, a downstream sieve $(\mathrm{d}=2.1 \mathrm{~mm})$ is set to delump possible agglomerates. The powder leaves the upper region and arrives in the conical mixing region, where a second impeller is mounted. The whole setup of the CMT is attached to load cells, which monitor the weight of the powder within the mixer. This hold-up mass (HUM) is defined in the recipe and determines the mass, will always be mixed in the CMT continuously throughout the process. 


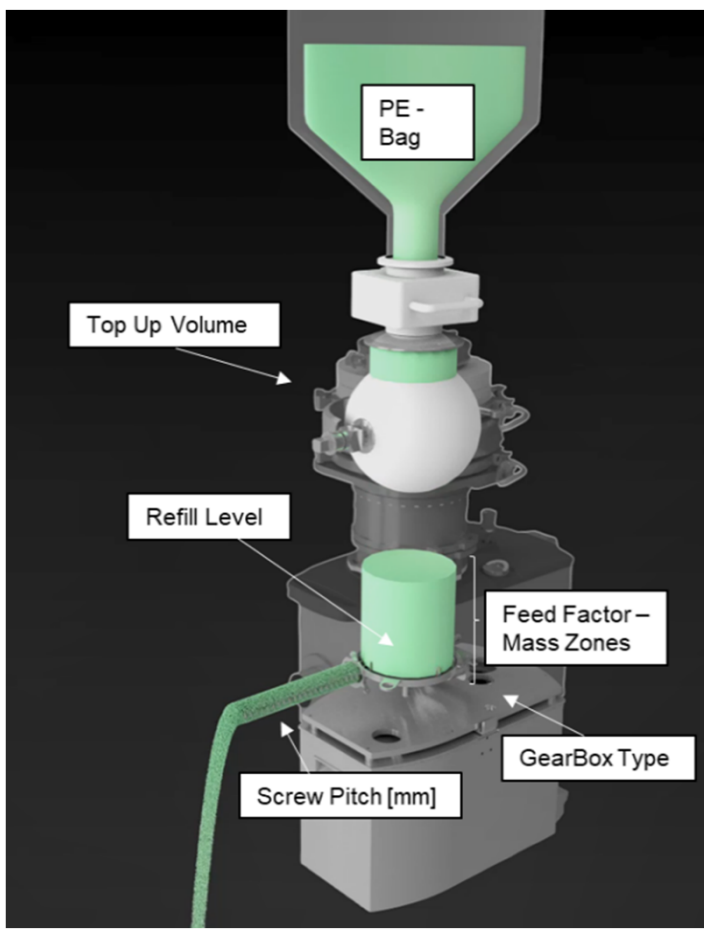

Figure 2. Overview of a GEA Compact Feeder and corresponding adjustment options.

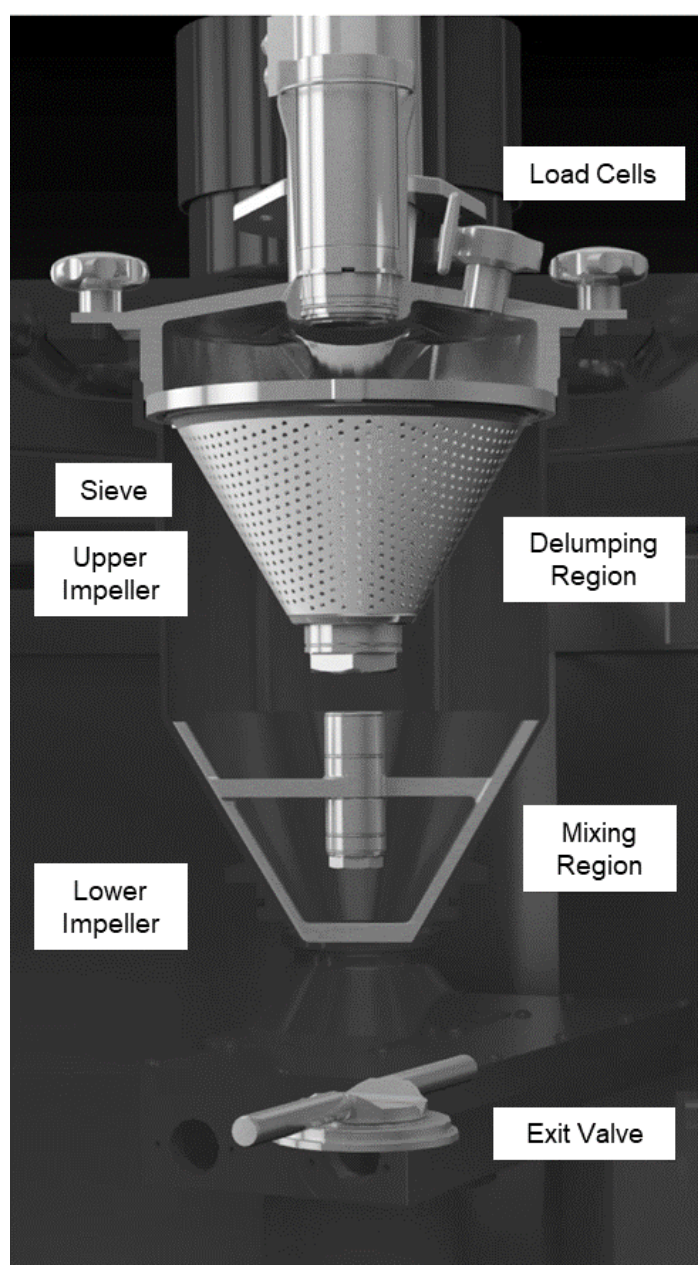

Figure 3. Overview of the CMT. View of the upper impeller is obstructed by the sieve. 
Other papers focus on a horizontal continuous mixer, where the HUM is considered a function of flow rate and impeller speed and cannot be set individually $[14,15]$. In contrast, the HUM in a vertical continuous mixer remains constant, and various shear rates (impeller speeds) can be applied despite a constant residence-time distribution (RTD) [8]. As in this case the continuous DC line includes only one mixing step for all mixture components, including the lubricant. An impact especially on lubricant-sensitive mixtures, as well as on the blend uniformity of the mixture and, subsequently, content uniformity of the tablets, can be expected [16-18].

The exit valve is located at the bottom of the CMT. By means of a proportional-integralderivative (PID) control loop, the exit valve opening width is adjusted automatically based on the current HUM value in order to keep the mass of the CMT constant. The controlled exit valve ensures that the same amount of mass entering the CMT will simultaneously leave the CMT (mass $_{\text {in }}=$ mass $_{\text {out }}$ ). Feed fluctuations of each feeder and the respective variability in the mass flow can be balanced that way. Smaller exit valve opening widths are recommended so that newly entering raw materials can be properly mixed together with the blend that is already present in the blender. Otherwise, unmixed or poorly mixed material can pass by and leave the CMT without being blended, causing content-uniformity variability [8].

The mean residence time (MRT, Equation (1)) of a particle can be calculated based on the overall throughput and the HUM. It reflects the mixing period of that particle within the CMT [8].

$$
\operatorname{MRT}[\mathrm{min}]=\frac{\operatorname{HUM}[\mathrm{kg}]}{\mathrm{THR}\left[\frac{\mathrm{kg}}{\mathrm{h}}\right]} * 60 \frac{\mathrm{min}}{\mathrm{h}}
$$

The total blade passes (TBP, Equation (2)) reveals how often the impeller, on average, will pass a particle and show the intensity of the shear transmitted to the powder. With an increasing number of revolutions and respectively increased shear, a lubricant, such as magnesium stearate (MgSt), can be introduced more homogeneously into the blend or even filmed onto the particles, potentially resulting in decreasing tensile strength of tablets. Therefore, particular attention is paid to the single mixing step in the CMT, where the lubricant will be mixed right from the start, together with the remaining raw materials, potentially resulting in a narrow process window between a homogeneous and an over-lubricated blend. Hence, it is required to set a suitable combination for HUM and IMP to ensure that TS and disintegration, as well as dissolution time, are within specification [19-25]. Thresholds regarding HUM and IMP are, besides the mass balance model (MBM), part of the control strategy of the CMT. If the process values exceed the specific limits, an alarm occurs and the process stops. Furthermore, variations in HUM and IMP could also impact the exit valve opening width and, therefore, the mixing quality.

$$
\mathrm{TBP}=\mathrm{MRT}[\mathrm{min}] * \mathrm{IMP}[\mathrm{rpm}]
$$

After the powder exits the CMT, it travels through the feed chute into the feed frame, where powder will be held up and be fed into the tablet press. Position sensors in the feed chute measure the filling levels. Using an internal feedback loop, we can control the turret speed of the tablet press according to the filling levels, thus preventing powder from backing up or the tablet press from running empty. An increasing feed-chute level results in an increased turret speed of the tablet press, i.e., increased powder demand, and vice versa.

The NIR probe in the feed frame is the first chemometric measurement in the process. It is therefore important to understand the impact of upstream settings and process states on the conformity of potency, as predicted by the NIR model.

The NIR probe measures a defined volume of the powder. The corresponding spectra are used to predict the API (active pharmaceutical ingredient) content. If inhomogeneity of the blend or variability in the upstream process units occurs, it can consequently be detected with NIR and is seen as a disturbance in the blend potency measured by NIR inside the feed frame [26]. 
Depending on the chosen control strategy, the impacted tablets can be diverted into the waste channel if the signals exceed the specification limits. As soon the signals are within specification limits again, the diverter switches back to the good product channel after a defined lead-lag time [27-29].

The tablet press was running with a control mode enabled, wherein the tablet weight control is based on the pre-compression displacement and the fill depth is adjusted accordingly. The bottom main compression height controls the thickness and compression force and, therefore, the crushing strength of the tablets. At the end of the tablet press, the tablets can be directed into the good channel, diverted into the waste channel or directed to the combi-tester, where at-line measurements regarding tablet properties can be performed in containment (see Section 2.7).

This paper assesses to what extent HUM, IMP and THR impact the downstream process of a direct compression mixture. It focuses on correlations and coherences and evaluates the predictability of process parameters based on the CMT settings, especially since the lubricant and all other formulation constituents are mixed simultaneously in one single mixing step. As a model formulation, Saccharin Monohydrate was used as API surrogate.

\section{Materials and Methods}

\subsection{Materials}

For this trial, saccharin sodium monohydrate (JMC, Ulsan, South Korea), microcrystalline cellulose (Avicel PH 102, FMC, Cork, Ireland), calcium di-phosphate (A-Tab, Innophos, Chicago Heights, IL, USA), sodium starch glycolate (Roquette, Lestrem, France) and magnesium stearate V (Mallinckrodt, St. Louis, MO, USA) were used.

\subsection{DoE Settings}

A central composite face design with a star points at the face of each side defined by a 2-level factorial design was conducted by using MODDE Pro 12.1 (Satorius Stedim Data Analytics AB, Umea, Sweden) (Table 2). A quadratic model was used, wherein the following parameters (Table 1) were considered:

Table 1. Overview of considered responses, where HUM, IMP and THR were adjusted as input variables.

\begin{tabular}{ll}
\hline Responses & \\
\hline Mixing parameters & $\mathrm{T}_{\mathrm{L},}$ \\
& $\mathrm{EV}$ \\
& Blend potency as predicted by the NIR model \\
\hline Material attributes of the blend & FRI \\
& Particle size $\left(\mathrm{d}_{10}\right)$ \\
\hline Tableting parameters & $\mathrm{CBD}$ \\
& $\mathrm{FD}$ \\
& $\mathrm{BCH}$ \\
& $\mathrm{EF}$ \\
\hline & $\mathrm{TS}$ \\
Tablet properties & $\mathrm{TT}$ \\
& $\mathrm{TW}$ \\
\hline
\end{tabular}

Compounds and composition remained constant over the entire experiment. In general, 17 runs, including 3 replicates of a center point, were performed (Table 2). After adjusting the new CMT parameters, a transition phase was initiated $(3 \times \mathrm{MRT})$ to wash out the powder mixed at the former setting. A compression-force profile was conducted by using 118, 157, 169, 236 and $275 \mathrm{MPa}$ compression pressure for each phase. Subsequently, the process was run for at least $10 \mathrm{~min}$ in a steady-state phase. 
Table 2. DoE settings, where phase 7, 9 and 11 are the replicates of the center point.

\begin{tabular}{cccccc}
\hline Phase & $\begin{array}{c}\text { Throughput } \\
(\mathbf{k g} / \mathbf{h})\end{array}$ & $\begin{array}{c}\text { Hold-Up Mass } \\
\mathbf{( g )}\end{array}$ & $\begin{array}{c}\text { Impeller Speed } \\
\mathbf{( r p m )}\end{array}$ & MRT (min) & TBP (rev) \\
\hline 1 & 10 & 400 & 200 & 2.4 & 480 \\
2 & 10 & 400 & 650 & 2.4 & 1560 \\
3 & 10 & 600 & 425 & 3.6 & 1530 \\
4 & 10 & 800 & 200 & 4.8 & 960 \\
5 & 10 & 800 & 650 & 4.8 & 3120 \\
6 & 20 & 400 & 425 & 1.2 & 510 \\
7 & 20 & 600 & 425 & 1.8 & 765 \\
8 & 20 & 600 & 200 & 1.8 & 360 \\
9 & 20 & 600 & 425 & 1.8 & 765 \\
10 & 20 & 800 & 425 & 2.4 & 1020 \\
11 & 20 & 600 & 425 & 1.8 & 765 \\
12 & 20 & 600 & 650 & 1.8 & 1170 \\
13 & 30 & 400 & 200 & 0.8 & 160 \\
14 & 30 & 400 & 650 & 0.8 & 520 \\
15 & 30 & 600 & 425 & 1.2 & 510 \\
16 & 30 & 800 & 650 & 1.6 & 1040 \\
17 & 30 & 800 & 200 & 1.6 & 320 \\
\hline
\end{tabular}

During the transition phase and the compression-force profile, the tablet press was operated in manual mode, without using the combi-tester, to analyze tablet properties. In manual mode, samples were taken and weighed manually to select the correct fill depth. During each steady-state phase, manual mode was switched to automatic mode, in which the NIR probe was active. For each steady state phase, $275 \mathrm{MPa}$ compression pressure was set; a tablet sample was taken in the middle of the steady state phase, using the combi-tester; and a powder sample was withdrawn at the end of each steady state phase by opening the sampling port underneath the feed frame and collecting approximately $300 \mathrm{~g}$ of powder.

\subsection{Feeder Settings}

The continuous manufacturing line used was equipped with PID-controlled LiW feeders. To ensure consistent powder supply, the following feeder settings were used (Table 3).

Table 3. Feeder settings for each raw material.

\begin{tabular}{|c|c|c|c|c|c|}
\hline & $\begin{array}{l}\text { Microcrystalline } \\
\text { Cellulose }\end{array}$ & $\begin{array}{c}\text { Saccharin } \\
\text { Sodium Monohydrate }\end{array}$ & $\begin{array}{c}\text { Calcium } \\
\text { Di-Phosphate }\end{array}$ & $\begin{array}{l}\text { Sodium Starch } \\
\text { Glycolate }\end{array}$ & $\begin{array}{l}\text { Magnesium } \\
\text { Stearate }\end{array}$ \\
\hline Composition (\%) & 49.104 & 21.844 & 24.552 & 3 & 1.5 \\
\hline Top-Up Volume (L) & 1.6 & 1.2 & 1.6 & 1.2 & 0.8 \\
\hline Gearbox Type & $1(63: 1)$ & $2(235: 1)$ & $2(235: 1)$ & $3(455: 1)$ & $3(455: 1)$ \\
\hline Screw Pitch (mm) & 20 & 10 & 20 & 10 & 20 \\
\hline Refill Level $\left(\mathrm{dm}^{3}\right)$ & 0.5 & 0.74 & 0.3 & 0.25 & 1.5 \\
\hline
\end{tabular}

\subsection{Bulk and Tapped Density}

Bulk and tapped density were measured by using an Erweka SVM 222 (ERWEKA $\mathrm{GmbH}$, Langen, Germany) according to Ph.Eur. A $250 \mathrm{~mL}$ graduated flask was used and filled with an appropriate amount of powder of each raw material and blend. The initial volume and the volume $\left(\mathrm{V}_{0}\right)$ after 750 and 1250 taps were noted. Each sample was analyzed in triplicate. Hausner Ratio and Carr's Index were calculated as shown in Equations (3) and (4) and interpreted as shown in Table 4.

$$
\text { Hausner Ratio }=\frac{\rho_{\text {tapped }}}{\rho_{\text {bulk }}}
$$




$$
\text { Carr Index }=\frac{\rho_{\text {tapped }}-\rho_{\text {bulk }}}{\rho_{\text {tapped }}} * 100
$$

Table 4. Classification of Carr Index [30].

\begin{tabular}{cc}
\hline Flowability & Carr's Index \\
\hline Excellent & $<15$ \\
Correct & $15-25$ \\
Poor & $>25$ \\
\hline
\end{tabular}

\subsection{Freeman Powder Rheometer FT4}

The FT4 Powder Rheometer (Freeman Technology Inc., Worcestershire, UK) was used to characterize flow properties of powders and granulates. For this trial, 3 methods (stability and variable flow rate, powder compressibility and shear cell) were used to analyze the impact of CMT parameters on the flowability of the resulting blends.

\subsubsection{Stability and Variable Flow Rate}

In this trial, a cylindrical $25 \mathrm{~mm} \times 25 \mathrm{~mL}$ split vessel was used. After an initial condition cycle, the powder was split to obtain a defined amount of powder to ensure reproducible measurements. The actual testing consisted of seven alternating conditioning and test cycles where the blade was inserted in the powder bed and was moved downward, with a rotational blade tip speed of $100 \mathrm{~mm} / \mathrm{s}$, to remove history and operator influence. Subsequently, 4 cycles with decreasing blade tip speed $(100,70,40$ and $10 \mathrm{~mm} / \mathrm{s})$ were performed. The required energy is based on the resistance of the blade to flow in the downward motion [31].

The basic flow energy (BFE) is defined by the required energy to move the blade downward at test-cycle 7. The specific energy (SE) represents the energy that is required during an upward traverse at the same test cycle. The stability index (SI) is calculated by the ratio of the energy at test-cycle 7 and test-cycle 1 . The flow-rate index (FRI) reflects the results of the reducing blade-tip speed, where the energy of the lowest rotational speed and the highest is set in ratio.

$$
\text { FRI }=\frac{\text { energy test } 11\left(10 \frac{\mathrm{mm}}{\mathrm{s}}\right)}{\text { energy test } 8\left(100 \frac{\mathrm{mm}}{\mathrm{s}}\right)}
$$

Basically, at higher flow rates, less energy is required, since the entrained air acts as a lubricant. At lower flow rates, the powder in front of the blades is more likely to be consolidated, due to the absence of entrained air; therefore, the interlocking of particles is more probable. Consequently, higher FRI values are common for cohesive powders. In this study, FRI values $<1$ are shown; they are typical for powders or blends containing lubricants. The conditioned bulk density (CBD) was measured after the initial conditioning cycle and the split of the powder, where agglomerates and air inclusions could be evened to ensure reproducible measurements [11,30,32-34].

\subsubsection{Powder Compressibility}

The compressibility method was used to investigate how the density of the measured powder changes with increasing normal stress. A split vessel $(25 \mathrm{~mm} \times 10 \mathrm{~mL})$ was used for this trial. After three conditioning cycles, the powder was split, and the blade was changed for a vented piston. In total, 8 compression steps were performed $(1,2,4,6,8$, 10,12 , and $15 \mathrm{kPa}$ ) and were held for $60 \mathrm{~s}$ at each force. In this work, only compressibility (change in volume after compression (\%)) was used. Low compressibility values occurred for powders with a low amount of entrained air where particles are packed compactly. High compressibility values were seen if voids within the powder occurred. This was likely with cohesive powders $[30,35]$. 


\subsubsection{Shear Cell}

A shear cell test was performed by using the FT4. For this method, a $25 \mathrm{~mm} \times 10 \mathrm{~mL}$ split vessel was used. As normal stress, 7, 6, 5, 4 and $3 \mathrm{kPa}$ were adjusted, and the initial consolidation stress was $9 \mathrm{kPa}$.

For this method, a $\tau-\sigma$-diagram can be obtained, where one pre-shear point and five yield points can be observed. Using a Mohr circle analysis, a linearized yield locus can be obtained, where the $\tau$-axis intersection is interpreted as cohesion and presents the obtained shear stress during powder deformation when no normal stress is applied [11,36-39].

\subsection{Particle Size Distribution}

For particle size measurements, a Sympatec QicPic (Sympatec GmbH, ClausthalZellerfeld, Germany) was used. It is a dynamic high-speed image-analysis system with a LED pulse-light source and high-resolution high-speed camera. An M7 lens was used that covers particles between 4.2 and $2888 \mu \mathrm{m}$. Dispersion pressure was set to 1 bar for all raw materials and blends to maintain comparability. A dry dispersion line RODOS/L with VIBRI attachment was in place, and the sample size remained constant for each material ( $5 \mathrm{~mL}$ ). To determine the particle size, the EQPC method was used, where $d_{10}, d_{50}$ and $d_{90}$ values were obtained (see Supplementary Table S34).

\subsection{Tableting}

A MODUL ${ }^{\mathrm{TM}} \mathrm{P}$ tablet press (GEA Pharma Systems, Courtoy ${ }^{\mathrm{TM}}$, Halle, Belgium) was implemented at the end of the continuous manufacturing line. Mode 2 (Courtoy dual-control force method) was selected, where the tablet weight control is based on pre-compression displacement measurements adjusting the fill depth, accordingly [40].

Round convex tablets with an $11 \mathrm{~mm}$ diameter and $1.12 \mathrm{~mm}$ cup height were manufactured. During steady state, a target compression pressure of $275 \mathrm{MPa}$ was set.

The target tablet weight of $600 \mathrm{mg}$, tablet crushing strength and tablet thickness were tested periodically in the middle of each steady state, using the at-line combi-tester (Kraemer Elektronik GmbH, Darmstadt, Germany).

The feed chute level was controlled to a constant level at $40 \%$, and the paddle speed remained constant at 45 and $40 \mathrm{rpm}$. Turret speed set-points and speed tolerances of the tablet press were adapted to the respective mass throughput (11 rpm $\pm 2.2 \mathrm{rpm}$; $21 \mathrm{rpm} \pm 4.2 \mathrm{rpm}$ and $32 \mathrm{rpm} \pm 6.4 \mathrm{rpm})$.

Tensile Strength

The tensile strength of the convex round tablets was calculated based on the following equation [41]:

$$
\text { Tensile Strength }=\frac{10 P_{s}}{\pi D^{2}}\left(2.84 \frac{t}{D}-0.126 \frac{t}{W}+3.15 \frac{W}{D}+0.01\right)^{-1}
$$

where $P_{S}=$ tablet core crushing strength, $D=$ tablet core diameter, $t=$ tablet core thickness and $W=$ cylinder length. Tablet-crushing strength was measured by using the combi-tester, which is directly connected to the continuous manufacturing line.

\subsection{Blend Potency}

To analyze the impact of the CMT settings on the blend potency, an NIR spectrometer (SentroProbe DR LS NIR 170C ATEX, Sentronic GmbH, Dresden, Germany) was installed in the feed frame, with an insertion depth of $1 \mathrm{~mm}$. Using PharmaMV 5.3 (Perceptive Engineering, Daresbury, UK), we recorded a spectrum every 4 s. Approximately 150-200 mg of the blend was measured during one measurement cycle. The collected data were preprocessed by first applying the Savitzky-Golay filter and then the standard normalize variate method (SNV). After that, the data were processed by a partial least square (PLS) regression model. The integration time was $9 \mathrm{~ms}$, with 133 average scans. 


\subsection{Software}

\subsubsection{MODDE}

The DoE was designed by using MODDE Pro 12.1. A multiple linear regression (MLR) model was used to evaluate the significance of the input factors on the responses. Furthermore, MODDE was used to obtain model equations to predict the responses.

\subsubsection{Osi $\mathrm{Pi}$}

A considerable benefit of the PCMM is the implementation of OsiPi (OsiSoft, San Leandro, CA, USA), which enables access to all essential process values. All data generated by the PCMM are continuously monitored and stored by using OsiPi.

$\mathrm{Pi}$ Vision is a web-based tool wherein process data can be visualized in real time. Since the process data are stored in the PI Server, PiVision also can visualize previous batches if process states need to be evaluated retrospectively. For this trial, all process-related data were gathered by using PiDataLink, which is an Add-In to Excel (Microsoft Corporation, Redmond, Washington, USA) that enables data to be imported from the PI Server.

\subsubsection{GraphPad Prism}

GraphPad Prism 9 (GraphPad Software, Inc., San Diego, CA, USA) was used to generate the figures and to calculate the correlations (Pearson correlations) between the process parameters, including the $p$-values. All correlation coefficients are shown Supplementary Figure S57. To evaluate the size of the correlation, the following thumb rule was used (Table 5):

Table 5. Interpretation of Pearson correlation coefficients [42].

\begin{tabular}{lc}
\hline Correlation Coefficient & Interpretation \\
\hline 0.9 to $1.0(-0.9$ to -1.0$)$ & Very high correlation \\
0.7 to $0.9(-0.7$ to -0.9$)$ & High correlation \\
0.5 to $0.7(-0.5$ to -0.7$)$ & Moderate correlation \\
0.3 to $0.5(-0.3$ to -0.5$)$ & Low correlation \\
0.0 to $0.3(-0.0$ to -0.3$)$ & Negligible correlation \\
\hline
\end{tabular}

\section{Results and Discussion}

\subsection{DoE Results}

The DoE reveals to what extent the input variables throughput (THR), hold-up mass (HUM) and impeller speed (IMP) affect the response parameters, such as the exit valve opening width and SD, torque of the lower impeller and corresponding SD, HUM SD and blend potency uniformity, as measured by NIR, in regard to the mixing step. Furthermore, the impact on material attributes of the blend (FRI, CBD and $\mathrm{d}_{10}$ values), tablet press parameters (FD, BCH and EF) and tablet properties (TS, TW, TT and corresponding standard deviation) are presented. A visualization where responses are expected is shown in Figure 4. The data were fitted by using an MLR model, wherein significant model terms are identifiable when error bars $(=95 \%$ confidence interval) do not cross the zero-line. Corresponding-fit statistics are shown in Supplementary Tables S2-S33. In this paper, models with $\mathrm{Q}^{2}>0.500$ (=estimate of prediction precision) and $\mathrm{R}^{2} \geq 0.800$ (=model fit) are considered good models, indicating a significant correlation between input variables and responses.

\subsubsection{Mixing Parameters}

For each presented response regarding mixing quality, impeller speed is a significant model term (Figure 5). The DoE showed that the influence on the exit valve opening width is driven by THR and IMP, resulting in higher opening widths if throughput and impeller speed are high as well. Regarding variability in EV, torque and blend potency, the impeller speed is the only significant model term. For torque values, HUM and IMP seem to share 
the same extent of deflection. With regard to HUM SD values, all three input factors and HUM*IMP were significant.

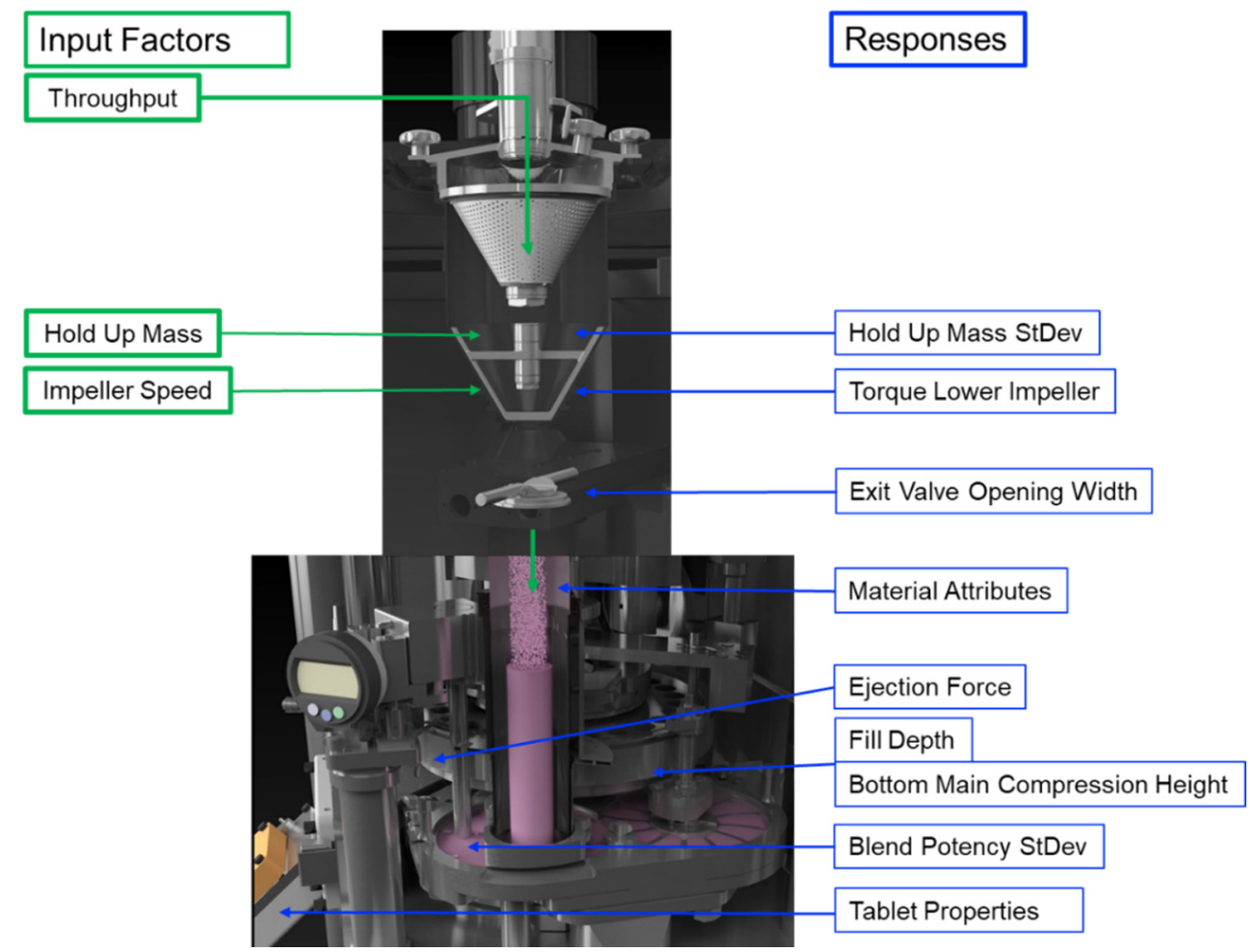

Figure 4. Process overview of input factors (green, left side) and observed responses (blue, right side).

$\mathrm{EV} \sim$

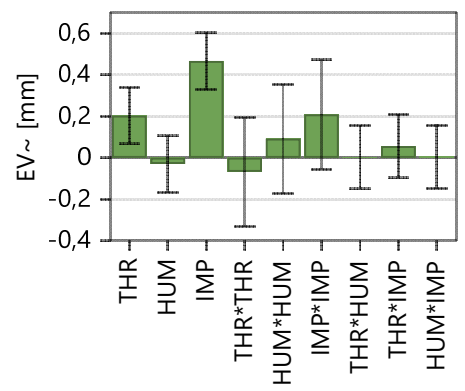

TL SD

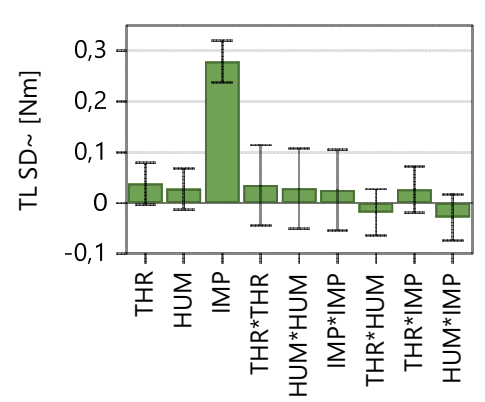

EV SD

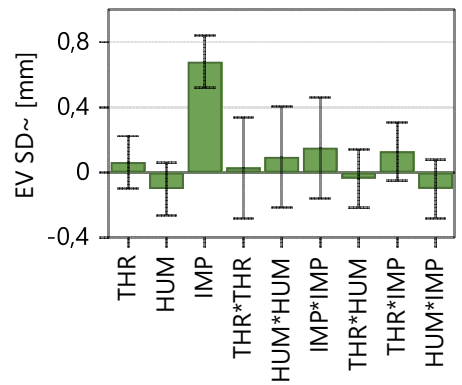

Blend Potency SD

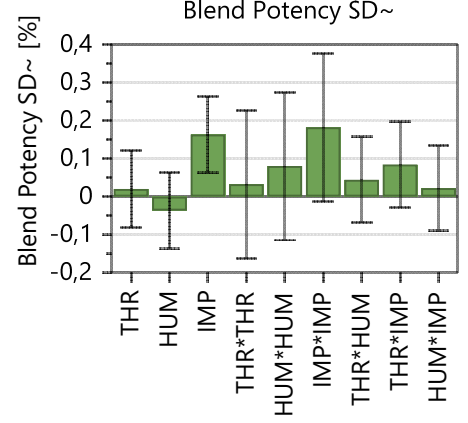

$\mathrm{TL} \sim$

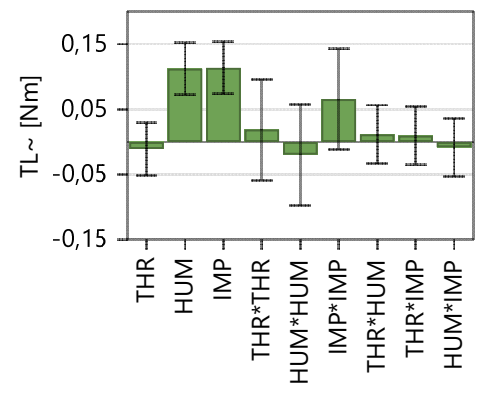

HUM SD

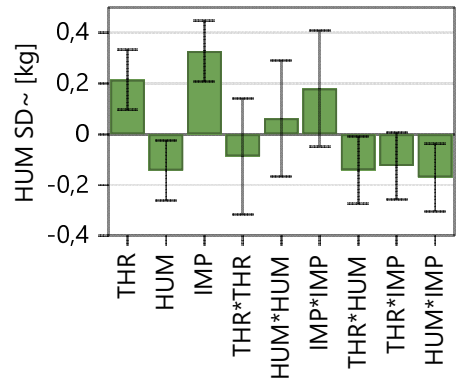

Figure 5. Coefficients plot of the impact of input variables on responses regarding the blending unit and uniformity of the blend. The $95 \%$ confidence interval is displayed as an error bar.

As shown in Table 6, Q2 and R2 imply, that exit valve opening width (+SD) and torque $(+\mathrm{SD})$ can be considered good models. As the variabilities of the responses were 
not linearly distributed a logarithmic data transformation was conducted (as shown in the corresponding chapters and Supplementary Figures S7 and S11).

Table 6. Overview of fit statistics regarding mixing parameters after removing non-significant model terms.

\begin{tabular}{ccccc}
\hline Response Factor & Data Transformation & $\mathbf{Q}^{\mathbf{2}}$ & $\mathbf{R}^{\mathbf{2}}$ & Adjusted $^{\mathbf{2}}$ \\
\hline Exit Valve Opening Width & Logarithmic & 0.860 & 0.905 & 0.883 \\
Exit Valve Opening Width SD & Logarithmic & 0.822 & 0.933 & 0.893 \\
Torque Lower Impeller & Logarithmic & 0.851 & 0.916 & 0.896 \\
Torque Lower Impeller SD & Logarithmic & 0.882 & 0.949 & 0.933 \\
Blend Potency SD & Logarithmic & 0.491 & 0.669 & 0.622 \\
HUM SD & Logarithmic & 0.428 & 0.727 & 0.664 \\
\hline
\end{tabular}

Further details regarding fit statistics and model equations are shown in Supplementary Section A, "Summary of Fit: Mixing Parameter".

\subsubsection{Material Attributes of the Blend}

The conditioned bulk density (CBD), flow-rate index (FRI) and $\mathrm{d}_{10}$ values of the blend were evaluated (Figure 6). THR, HUM and IMP show a similar impact on CBD and $d_{10}$ values of the powder. In contrast, the coefficients regarding FRI show a positive impact of THR and a negative influence by IMP and THR*THR.
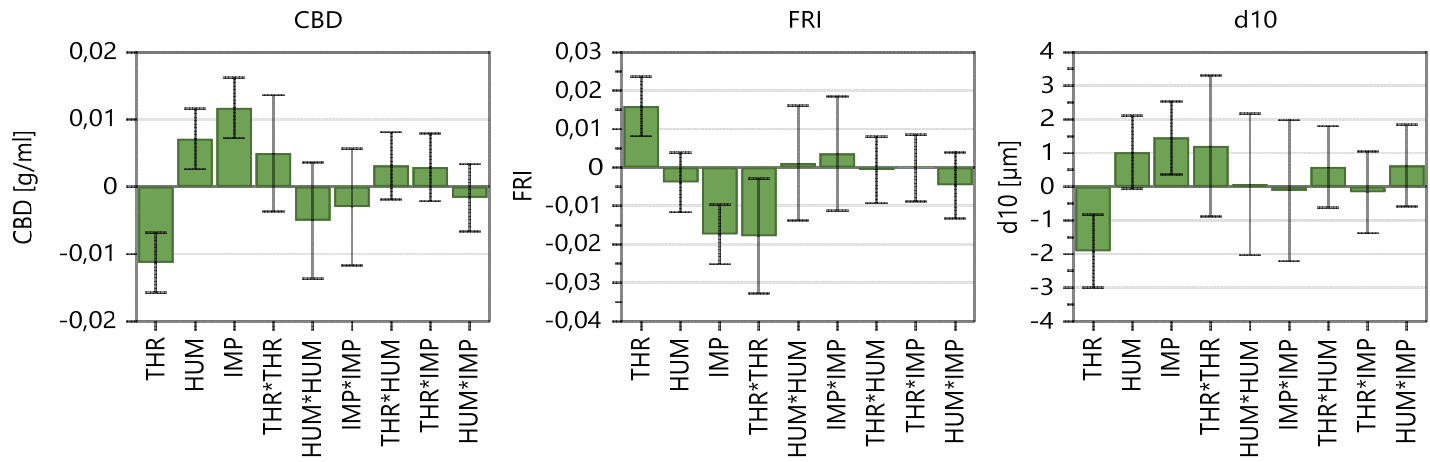

Figure 6. Coefficients plot of model terms regarding material attributes of the blends. The 95\% confidence interval is displayed as an error bar.

Table 7 shows the fit statistics after removing non-significant model terms, whereby models regarding CBD, FRI and $\mathrm{d}_{10}$ can be considered good models. For further details, see Supplementary Section B, "Summary of Fit: Material Attributes of the Blend".

Table 7. Overview of fit statistics regarding material attributes of the blend.

\begin{tabular}{ccccc}
\hline Response Factor & Data Transformation & $\mathbf{Q}^{\mathbf{2}}$ & $\mathbf{R}^{\mathbf{2}}$ & Adjusted $^{\mathbf{2}}$ \\
\hline Conditioned Bulk & - & 0.735 & 0.850 & 0.816 \\
$\quad$ Density & - & 0.800 & 0.896 & 0.848 \\
Flow Rate Index & - & 0.587 & 0.842 & 0.747 \\
Particle Size $\left(\mathrm{d}_{10}\right)$ & & & \\
\hline
\end{tabular}

\subsubsection{Tableting Parameters}

Regarding tableting parameters, the fill depth, bottom main compression height and ejection force were evaluated, wherein throughput and impeller speed are significant model terms for all three parameters (Figure 7). That means, these input factors have a statistically significant impact on all three tableting parameters. For example, higher throughput and 
lower impeller speed result in lower TBP and, therefore, in lower lubrication, leading to lower powder densities, higher required fill depths and higher ejection forces.
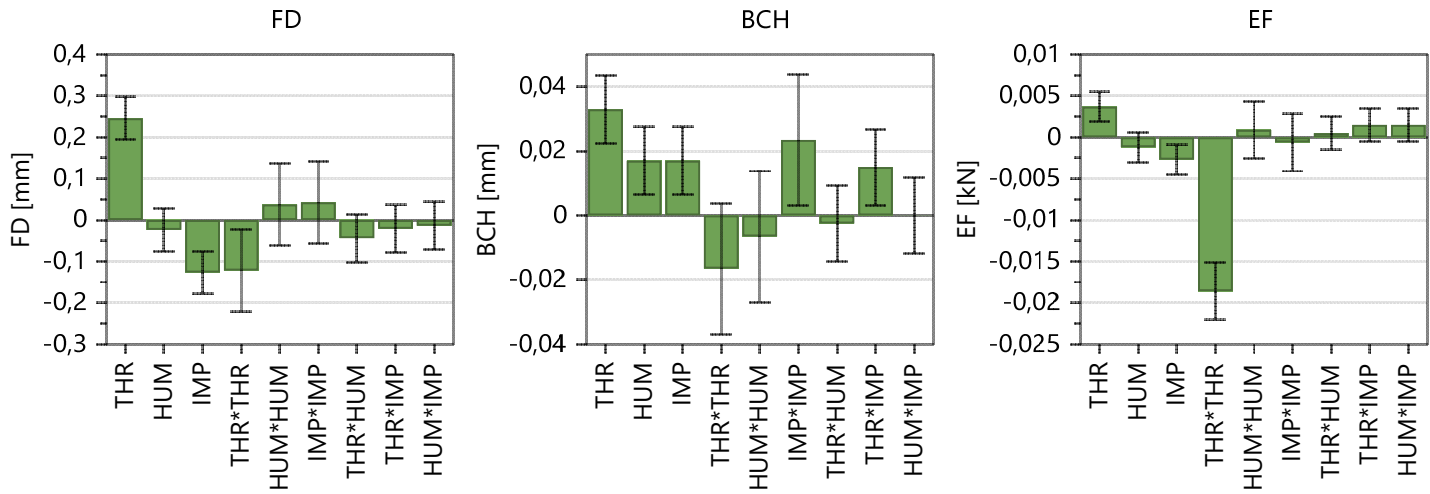

Figure 7. Coefficients plot of model terms regarding tablet press parameters. The $95 \%$ confidence interval is displayed as an error bar.

Furthermore, the fill depth and ejection force share the same deflection of the three significant model terms, namely THR, IMP and THR*THR.

Table 8 shows the fit statistics after removing non-significant model terms. All three parameters show high values regarding $\mathrm{Q}^{2}$ and $\mathrm{R}^{2}$. For further information regarding fit statistics and model equations, see Supplementary Section C, "Summary of Fit: Tablet Press Parameters".

Table 8. Overview of fit statistics regarding tablet-press parameters.

\begin{tabular}{ccccc}
\hline Response Factor & Data Transformation & $\mathbf{Q}^{\mathbf{2}}$ & $\mathbf{R}^{\mathbf{2}}$ & ${\text { Adjusted } \mathbf{R}^{\mathbf{2}}}^{\mathbf{2}}$ \\
\hline Fill Depth & - & 0.873 & 0.941 & 0.914 \\
Bottom Main & - & 0.774 & 0.928 & 0.885 \\
Compression Height & - & 0.892 & 0.944 & 0.931 \\
Ejection Force & - & &
\end{tabular}

\subsubsection{Tablet Properties}

To investigate the impact of CMT parameters on the tablet properties, the tensile strength (TS), tablet weight (TW) and tablet thickness (TT) obtained during steady state at $275 \mathrm{MPa}$ compression pressure were evaluated.

In Figure 8, it can be observed that, besides the three input factors, namely THR, HUM and IMP, THR ${ }^{*}$ THR, THR*IMP and HUM*IMP are significant model terms for tensile strength. That means, higher THR, lower HUM and lower IMP resulted in lower TBP and, therefore, lower lubrication, which increased the tensile strength of the tablets. Further explanations regarding TBP and tablet properties can be seen in the paragraph "Tensile Strength".

On the other hand, the tablet weight and thickness are both influenced by similar input variables. As the tablet-weight variance was always within control limits, an automatic weight adjustment did not occur. Consequently, TW was impacted by the density of the blends and FD. Considering the MLR, the high IMP, high IMP2 and high THR*IMP resulted in higher TBP and higher densities. Since the FD adjustments only occurred occasionally when the displacement at the pre-compression exceeded internal limits at which the calculated weights are too high/low, higher powder density resulted in higher TW. Regarding variability in tablet properties, throughput has the highest impact on tablet weight and thickness standard deviations, whereas no significant model term regarding TS SD could be found. 


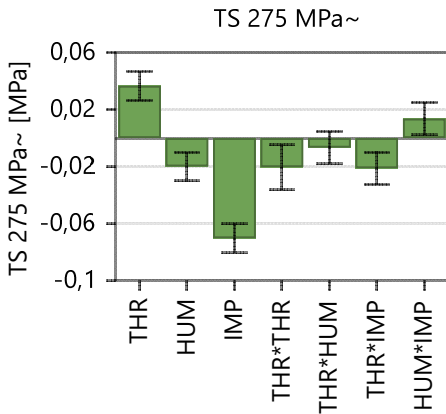

TS $275 \mathrm{MPa}$ SD

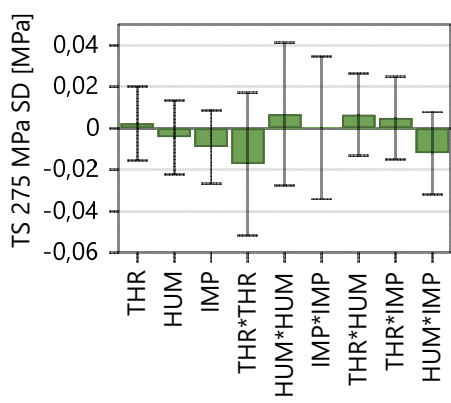

TW $275 \mathrm{MPa}$

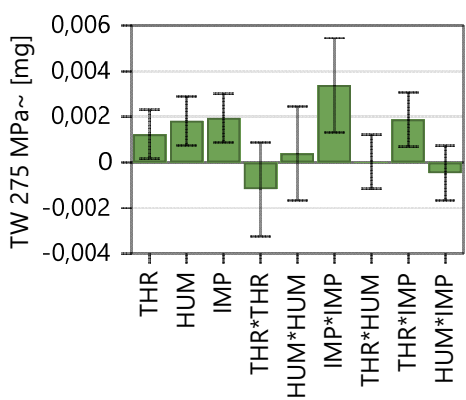

TW 275 MPa SD

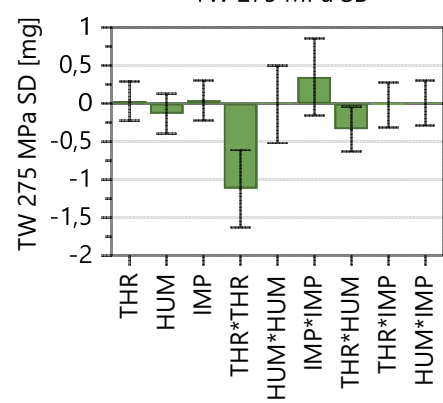

TT $275 \mathrm{MPa}$

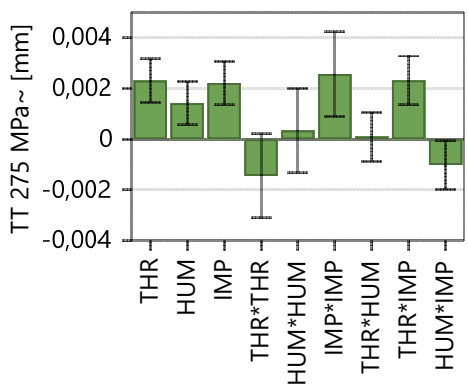

TT 275 MPa SD

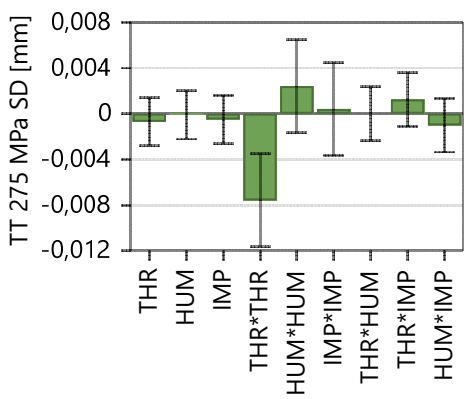

Figure 8. Model terms regarding tensile strength (TS), tablet weight (TW), tablet thickness (TT) and corresponding standard deviation. The $95 \%$ confidence interval is displayed as an error bar.

According to Table 9, tensile strength, tablet weight and tablet thickness can be considered good models. Again, as the variabilities of the responses were not linearly distributed, a logarithmic data transformation was conducted. Corresponding figures, model equations and fit statistics are shown in Supplementary Section D, "Summary of Fit: Tablet Properties".

Table 9. Overview of fit statistics regarding tablet properties.

\begin{tabular}{ccccc}
\hline Response Factor & Data Transformation & $\mathbf{Q}^{\mathbf{2}}$ & $\mathbf{R}^{\mathbf{2}}$ & Adjusted $\mathbf{R}^{\mathbf{2}}$ \\
\hline Tensile Strength & Logarithmic & 0.907 & 0.976 & 0.958 \\
Tensile Strength SD & - & -0.090 & 0.283 & 0.117 \\
Tablet Weight & Logarithmic & 0.641 & 0.904 & 0.847 \\
Tablet Weight SD & - & 0.472 & 0.856 & 0.770 \\
Tablet Thickness & Logarithmic & 0.718 & 0.953 & 0.917 \\
Tablet Thickness SD & - & 0.395 & 0.694 & 0.592 \\
\hline
\end{tabular}

\subsection{Response Factors}

For recapitulation, Figure 9 demonstrates the relationships between all parameters obtained and evaluated within this DoE. Starting from the CMT settings, the flowchart depicts the downstream process parameters where correlations are expected to be found.

\subsubsection{Mixing Parameters \\ Exit-Valve-Opening Width}

As presented in Figure 5, the throughput and impeller speed were the significant model terms for the exit valve opening width $\left(Q^{2}=0.860\right.$ and $\left.R^{2}=0.905\right)$. The low model validity observed was due to the extremely low variability seen in the replicated center points, and, hence, it is not a cause for concern.

In this regard, Figure 11a shows the exit valve opening width dependent on overall mass throughput, wherein increasing the throughput led to an increasing opening width. Furthermore, all EV at $650 \mathrm{rpm}$ were higher than $10 \mathrm{~mm}$. Figure $11 \mathrm{~b}$ shows the exit valve depending on impeller speed. It confirms that the high impeller speed was an important 
reason for an increasing EV, while variations in HUM seemingly did not impact the exit valve $(0.042 p=0.874)$. Furthermore, a contour plot is used to demonstrate the significance of both model terms throughput and impeller speed (Figure 10). To determine suitable CMT settings based on this plot, small exit valve opening widths $(<5 \mathrm{~mm})$ are preferable, which is in line with the findings of Toson [8]. Additionally, data regarding blend potency $\mathrm{SD}$ confirmed the maximum of $5 \mathrm{~mm}$ opening value of the exit valve (further details below).

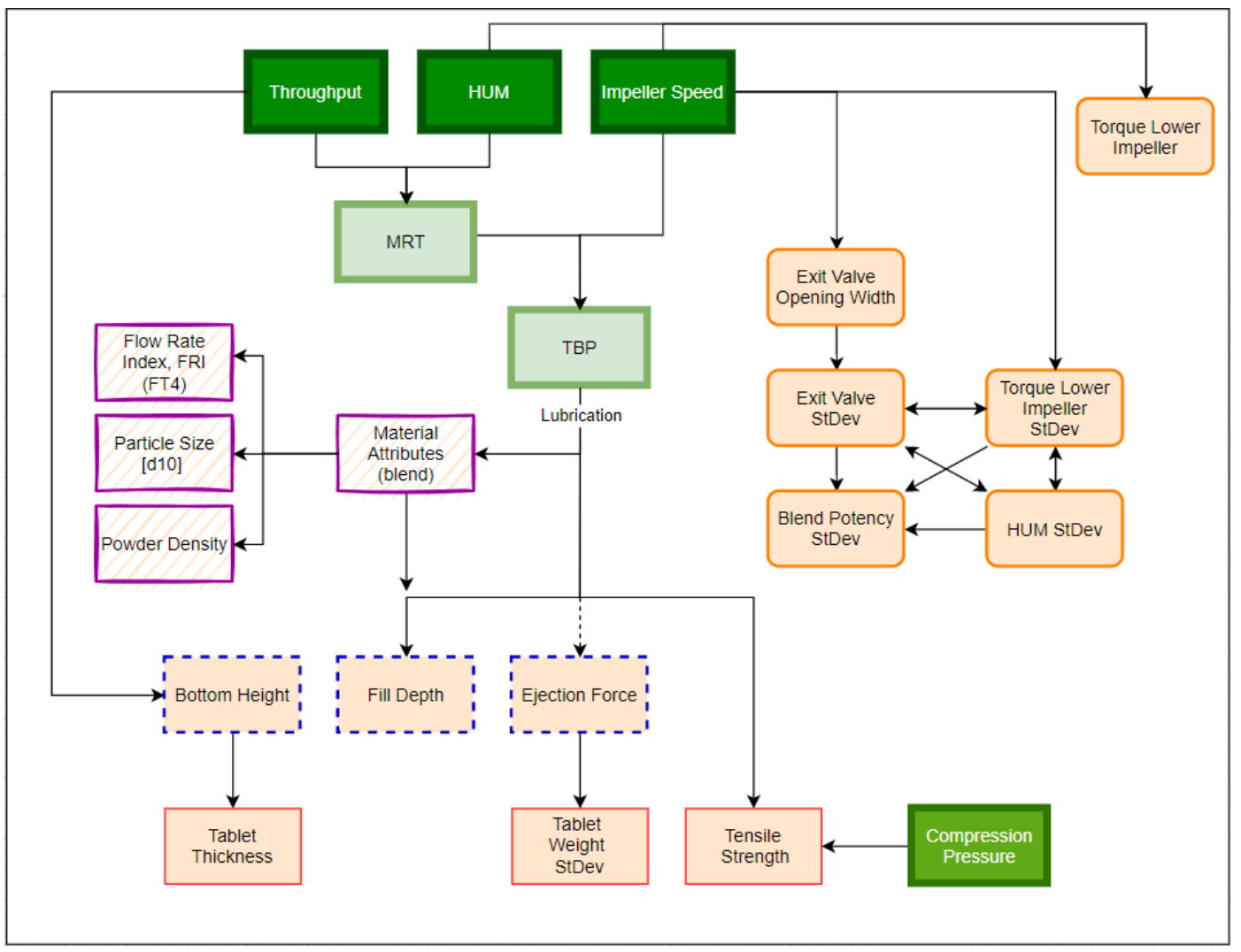

Figure 9. Qualitative overview of process parameter connections and correlations. Input factors are marked in dark green (thick borders), confounding input parameters are marked in light green and the considered response parameters are shown in light orange. The color/shape of the borders classifies the responses into mixing parameters (orange line, rounded corners), material attributes of the blend (purple, striped background), tableting parameters (blue, dotted borders) and tablet properties (red, thin borders). Compression pressure (green) is considered an independent input factor of the tablet press.
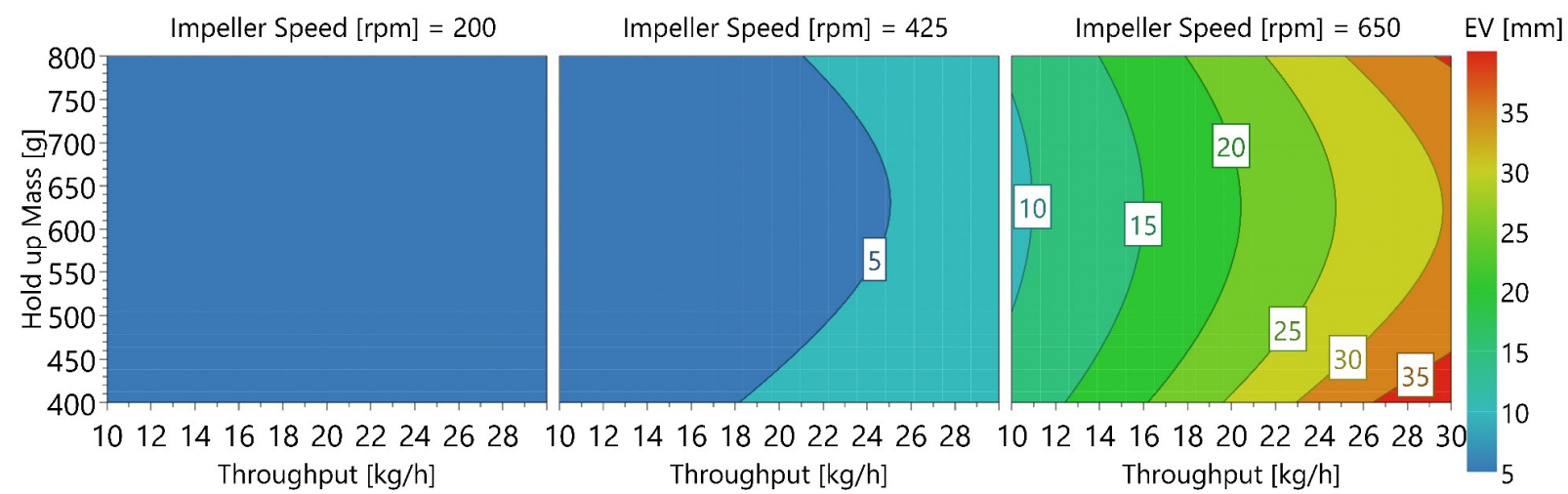

Figure 10. Contour plot of exit valve opening width in dependence of THR, HUM and IMP. 
Regarding EV SD, Table 6 reveals that impeller speed was the only significant model term $\left(Q^{2}=0.822 R^{2}=0.933\right)$. Furthermore, Figure 11c shows the EV standard deviation as a function of the EV opening width $(0.785 p=0.0002)$. This correlation leads to the conclusion that higher EV values increased the risk of a fluctuating opening width, impacting the variability of the blend potency values $(0.952 p<0.0001)$ and subsequently affecting content uniformity of the tablets. A correlation matrix with downstream parameters concerning the EV is shown in Figure 12.

(a)

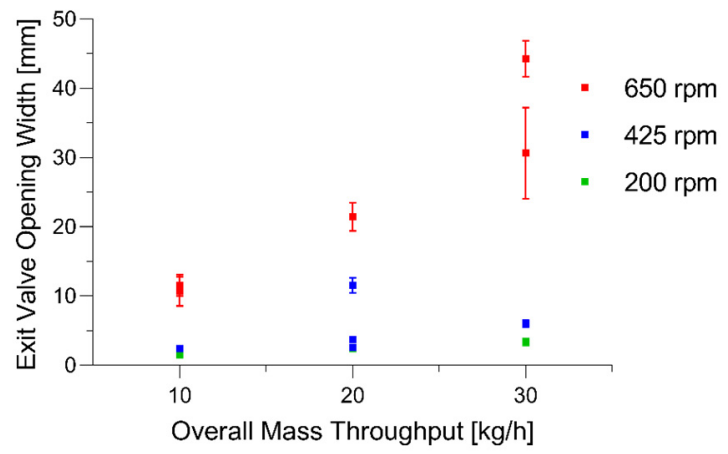

(c)

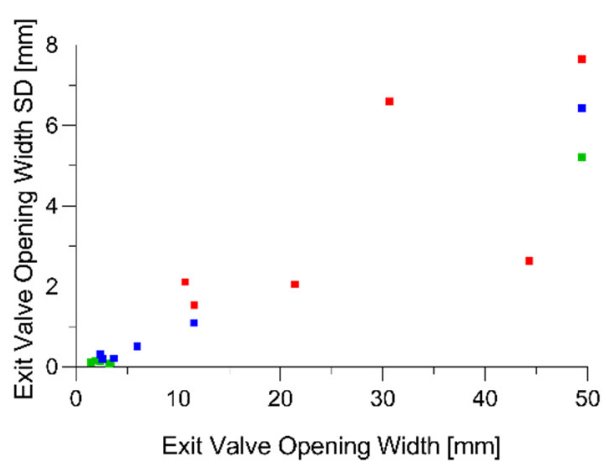

(b)

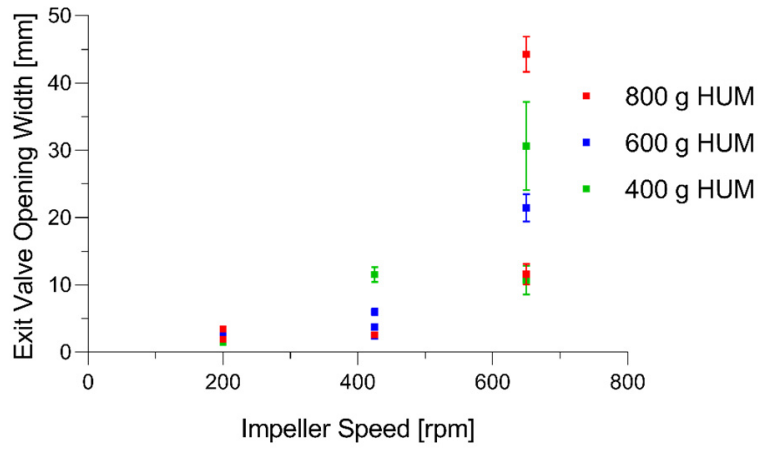

(d)

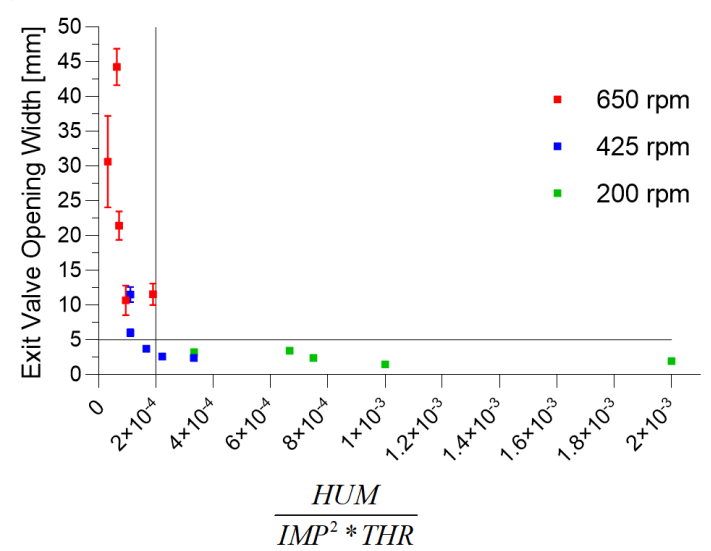

Figure 11. (a) Exit valve opening width vs. throughput $(\mathrm{kg} / \mathrm{h})$ in relation to varying impeller speeds. (b) EV in dependence of impeller speed. (c) EV SD vs. EV. (d) EV as function of $\frac{\mathrm{HUM}[\mathrm{g}]}{\mathrm{IMP}^{2}\left[\mathrm{rpm}^{2}\right] * \mathrm{THR}\left[\frac{\mathrm{kg}}{\mathrm{h}}\right]}$ where $\mathrm{x}$-values higher than $2 \times 10^{-4}$ result in EV below $5 \mathrm{~mm}$.

Figure $11 \mathrm{~d}$ shows a correlation of the EV with the ratio of $\frac{\mathrm{HUM}[\mathrm{g}]}{\mathrm{IMP}^{2}\left[\mathrm{rpm}^{2}\right] * \mathrm{THR}\left[\frac{\mathrm{kg}}{\mathrm{h}}\right]}$. This empirically found normalization revealed good processing for values exceeding $2 \times 10^{-4}$.

As the decreased impeller speed proved to have the highest impact on reducing the exit valve opening width, it is certainly the primary parameter for reducing the EV value below $5 \mathrm{~mm}$. However, one needs to consider the impact on the powder attributes of the blend, because a decrease in impeller speed will decrease the TBP and, therefore, the amount of lubrication. As described in the following sections, the TBP impacts the CBD, FRI, $\mathrm{d}_{10}$ values, FD and TS.

\section{HUM SD}

HUM is an essential variable in MRT and TBP (Equations (1) and (2)), and this is why it is crucial to choose suitable blender parameters to maintain a consistent process. Accordingly, the fluctuation in HUM led to variabilities in the MRT and TBP. 


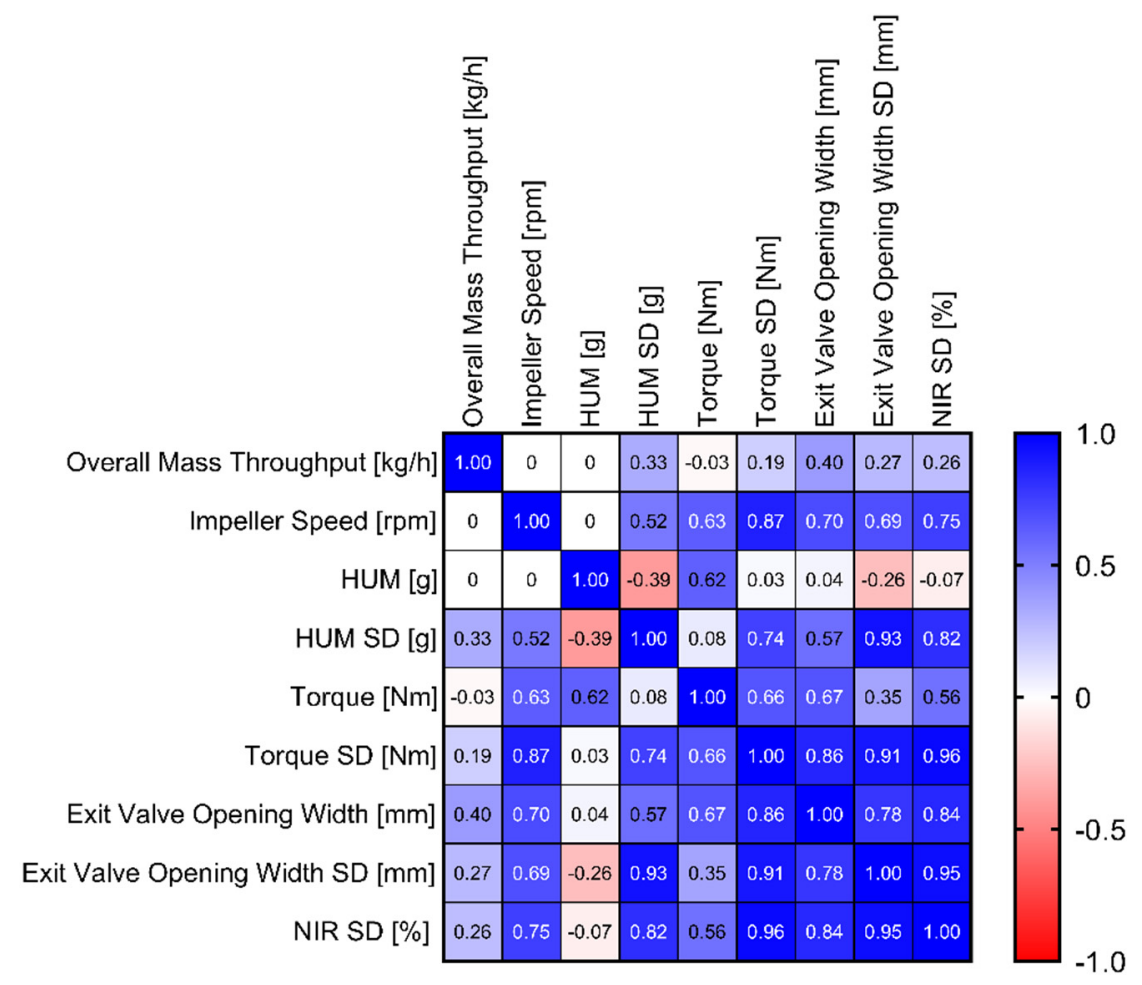

Figure 12. Correlation matrix of input variables and mixing parameters.

Figure 13a shows the HUM SD as a function of impeller speed (0.514 $p=0.035)$. It reveals that the HUM standard deviations were not directly impacted by throughput. However, throughput is a significant model term, since comparatively low HUM standard deviations were obtained at low throughputs. On the other hand, higher impeller speeds tended to result in a larger span of HUM SD, and this could be caused by an unfavorable powder bed shape, due to higher centrifugal forces, as described by Toson et al. [8].

(a)

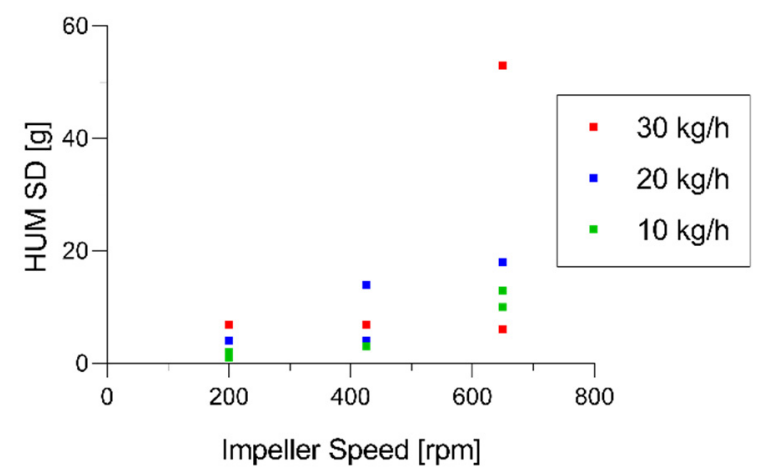

(b)

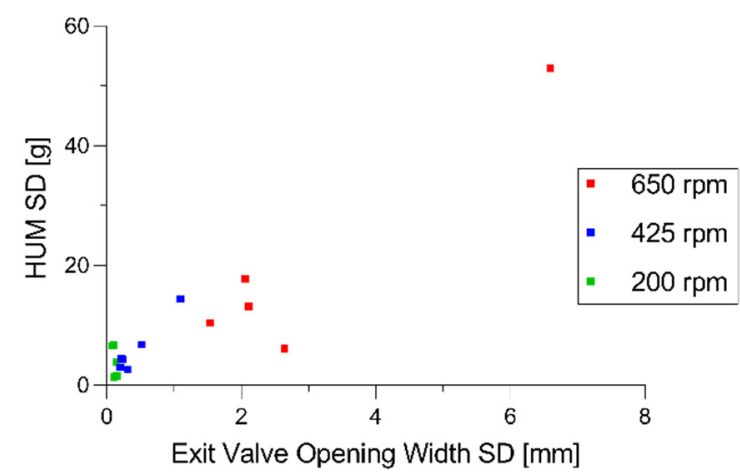

Figure 13. (a) HUM standard deviation as a function of impeller speed. (b) Dependencies between SD in EV and HUM.

Figure $13 \mathrm{~b}$ shows that the previously mentioned EV SD correlated with HUM SD $(0.929 p<0.001)$. That could be traced back to the PID control loop between HUM and $\mathrm{EV}$, where $\mathrm{EV}$ is a function of HUM process values in order to maintain mass in $=$ mass $_{\text {out }}$. Therefore, if variability could be observed in the HUM, then it occurred in EV, as well. To avoid those fluctuations, we can rely on the previous section, where impeller speed is 
the recommended parameter to control the corresponding process parameters. A detailed example is given in Supplementary Section E, "Additional Demonstration of HUM SD".

Torque of Lower Impeller

Regarding Table 6, the models for $\mathrm{T}_{\mathrm{L}}\left(\mathrm{Q}^{2}=0.851\right.$ and $\left.\mathrm{R}^{2}=0.916\right)$ and $\mathrm{T}_{\mathrm{L}} \mathrm{SD}\left(\mathrm{Q}^{2}=0.882\right.$ and $R^{2}=0.949$ ) could be considered good models. The low model validity for torque SD is, again, caused by low variability in the replicated center points, and, therefore, it is not a cause for concern. Basically, the torque represents the required energy to turn the impeller within the CMT and can be used to monitor the mixing process [43].

Since the model terms in Figure 5 showed similar coefficients of HUM and impeller speed, the torque could be seen as a function of the sum of both factors $(0.888 p<0.0001)$ (Figure 14a).

(a)

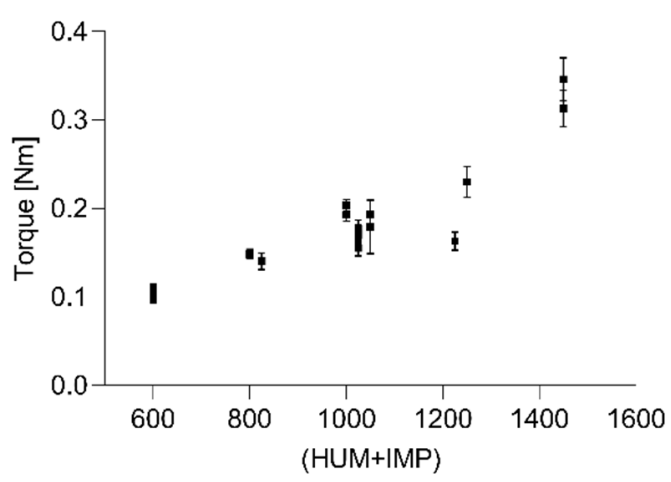

(c)

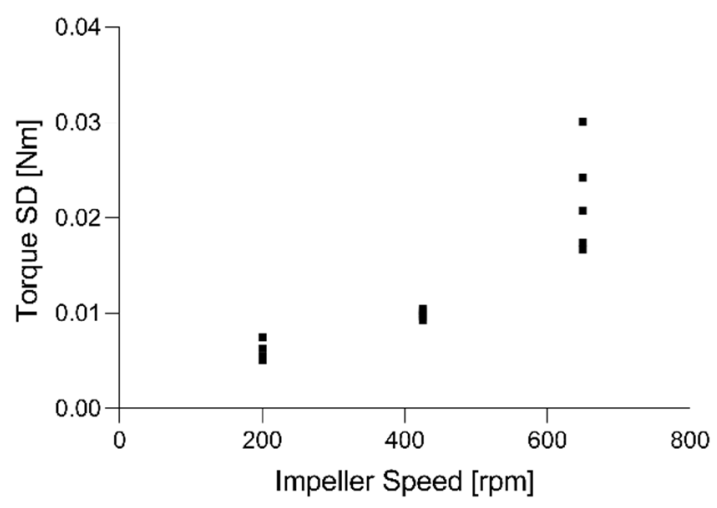

(b)

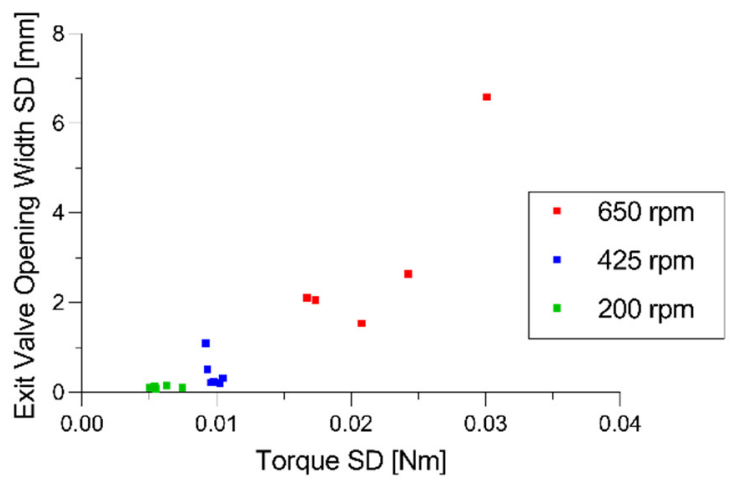

Figure 14. (a) Torque of the lower impeller as a function of the sum of HUM and IMP. (b) Correlation between variability in torque and exit valve opening width. (c) Impact of impeller speed on the torque values.

Figure 14b demonstrates the linearity between $\mathrm{T}_{\mathrm{L}}$ SD and EV SD $(0.906 p<0.0001)$. The correlation between these standard deviations is based on the impact of impeller speed (IMP- $\mathrm{T}_{\mathrm{L}}$ SD: $\left.0.874 p<0.0001\right)$, wherein the higher impeller rotation resulted in higher variabilities in both parameters (Figures 5 and 14c).

Since standard deviations in both the torque and exit valve were strongly correlated, it is recommended to only focus on the EV values if monitoring is required. 


\section{Blend Potency SD}

Reflecting previously described process parameters, the correlations between blend potency SD and EV $(0.843 p<0.0001)$, EV SD $(0.952 p<0.0001)$, HUM SD $(0.817 p<0.0001)$, $\mathrm{T}_{\mathrm{L}} \mathrm{SD}(0.965 p<0.0001)$ and IMP $(0.753 p=0.0005)$ could be observed (Figure 12).

Higher exit valve opening widths implicate that the powder bed was not entirely closed at the bottom of the CMT and that particles newly entering the CMT could exit unmixed [8]. Consequently, blend potency SDs and, therefore, blend inhomogeneities could be explained by insufficient mixing based on the structure of the powder bed within the blend. Figure 15a shows the blend potency standard deviation as a function of impeller speed, wherein all values at $650 \mathrm{rpm}$ were above $2.5 \%$. This observation could also be confirmed by using Figure 5, wherein IMP was the significant model term. Thus, to reduce blend potency SDs and, therefore, improve blend homogeneity and content uniformity of the tablets, reduction of the impeller speed is again proposed.

(a)

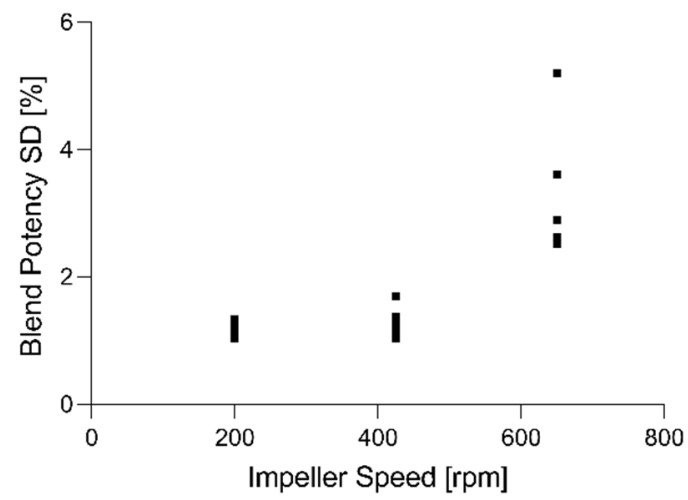

(b)

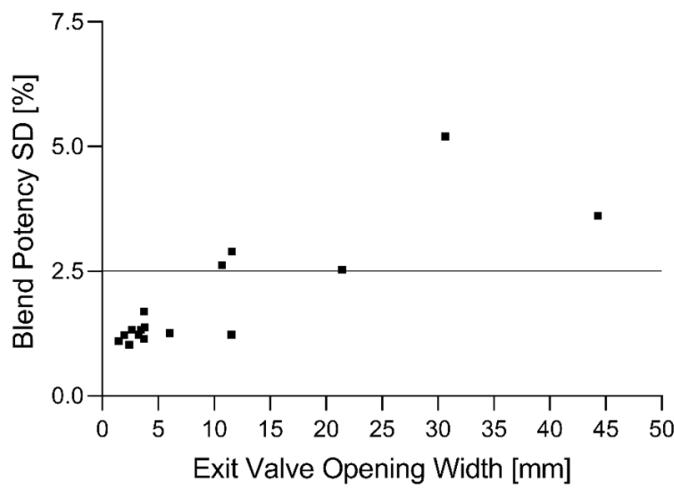

Figure 15. Blend Potency SD as a function of (a) impeller speed and (b) exit valve opening width.

Figure $15 \mathrm{~b}$ shows that all blend potency values obtained at exit valve opening widths below $10 \mathrm{~mm}$ were smaller than $2.5 \%$. To minimize the risk of a higher blend potency SD, the presented results confirm maximum EV values below $5 \mathrm{~mm}$.

Furthermore, independent of the blender variables, a potential risk for blend potency inhomogeneity could be adhesion of API at the walls due to electrostatic charging of particles [44].

\subsubsection{Material Attributes of the Blend}

During continuous mixing with a vertical blender, TBP is the decisive factor in describing the impact on material attributes since magnesium stearate will be mixed simultaneously throughout the entire mixing process. It is the combination of impeller speed and blend time (MRT) (Equation (2)), governing shear and mixing intensity of the lubricant into the blend. For improvements regarding EV position and HUM uniformity following changes in material attributes must be considered:

Higher TBP represents more contact between impeller and powder particles and hence, it is implied that lubricant can be distributed more homogeneously into the blend with the potential risk of film formation. This would impact the tablet tensile strength and will be further discussed in section Tensile Strength.

\section{Powder Density}

With more impeller revolutions, more cavities of particles and granules can be filled and a layer around the particles can be built. On one hand, that increases the weight without increasing the volume and on the other hand, it is reducing particle-particle frictions due to the reduced friction of magnesium stearate filmed particles. Particles can now arrange more compactly, increasing the powder density $[45,46]$. 
Figure 16a demonstrates an exponential relationship between TBP and CBD asymptotically reaching a value of $0.598 \frac{\mathrm{g}}{\mathrm{mL}}$ at $1560 \mathrm{TBP}$. At extreme values, such as 3120 revolutions, powder density will not increase any further and a maximum seemed to be reached, which led to the conclusion that increasing TBP only affected the material up to a certain limit.

(a)

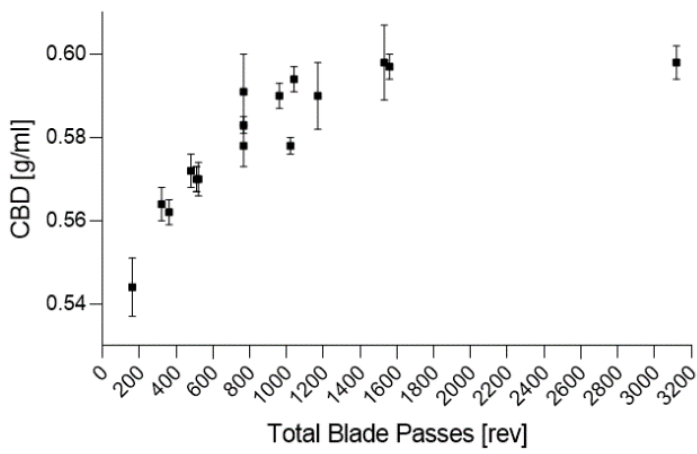

(b)

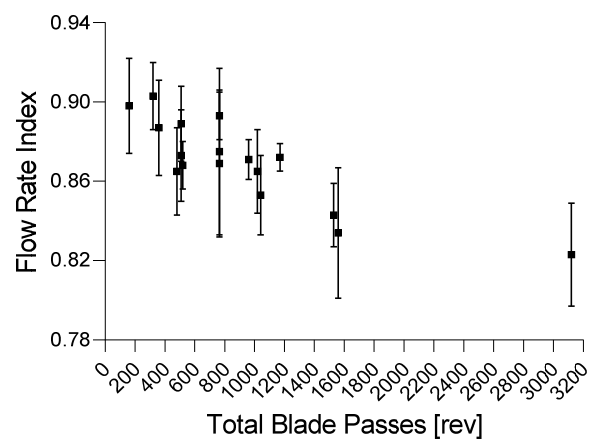

(c)

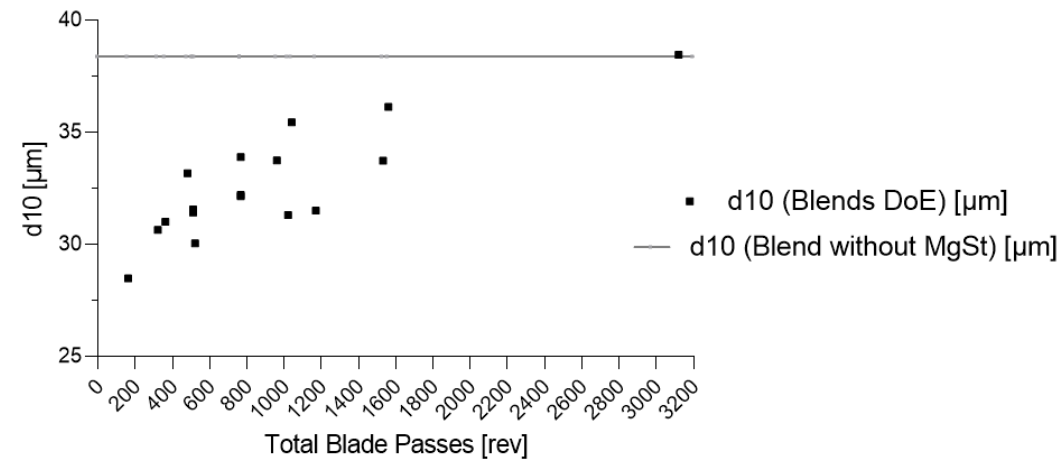

Figure 16. (a) Conditioned bulk density (CBD) (g/mL), (b) flow rate index (FRI) and (c) particle size $\left(\mathrm{d}_{10}\right)(\mu \mathrm{m})$ as a function of total blade passes.

Considering Figure 6 and the equation for TBP (Equation (2)), the significant model terms of the DoE revealed the same information, where higher values in HUM and impeller speed increased CBD, and higher throughputs decreased the powder density $\left(Q^{2}=0.735\right.$ and $\left.\mathrm{R}^{2}=0.850\right)$.

\section{Flow Rate Index}

Figure $16 \mathrm{~b}$ shows the flow rate index (FRI) as a function of TBP $(-0.846 p<0.0001)$. In contrast to CBD, the FRI decreased with the rising TBP. Due to an increasing lubrication effect at the higher TBP, less energy was needed to move the blade through the powder bed, since the required energy is based on the resistance at the downward motion. Again, a plateau could be observed wherein the increasing TBP did not necessarily impact the FRI any further. The MLR analysis showed a model fit of $Q^{2}=0.800$ and $R^{2}=0.896$.

\section{Particle Size}

The description of density changes based on TBP also applies to the particle size $\left(\mathrm{d}_{10}\right)$ (Figure 16c). At a high TBP, more magnesium stearate adhered to the particles, leading to a lower amount of the remaining free MgSt particles within the blend, and thus increasing the $\mathrm{d}_{10}$ values $(0.836 p<0.0001)$. As a reference, a blend without magnesium stearate was mixed by using a Turbula blender (Willy A. Bachofen AG, Muttenz, Switzerland), where a $\mathrm{d}_{10}$ value of $38.38 \mu \mathrm{m}$ was obtained (Figure $16 \mathrm{c}$ ). 
Therefore, the appearance of smaller particle sizes in the blend could be traced back to MgSt. As seen at 3120 revolutions, the $\mathrm{d}_{10}$ value was similar to the blend without MgSt, implicating that the fine fraction of $\mathrm{MgSt}$ was almost completely attached to the remaining raw materials at the higher TBP. Moreover, particle-size changes due to destruction of particles could be ruled out. In this case, the $\mathrm{d}_{10}$ values would have decreased with a higher shear.

Regarding the DoE results in Figure 6, a good model for $\mathrm{d}_{10}$ values could be obtained $\left(\mathrm{R}^{2}=0.842\right.$ and $\left.\mathrm{Q}^{2}=0.587\right)$. Particle sizes of raw materials and blends are shown in Supplementary Table S34.

\subsubsection{Tableting Parameters \\ Fill Depth}

Higher powder density (CBD) will result in lower fill depths to fulfill the weight requirements, which could be confirmed in this paper $(-0.844 p<0.0001)$. As described above, the density of the blend was a function of TBP; that was why the fill depth was adjusted according to changes in TBP $(-0.775 p<0.0001)$, as well. Figure 17a shows the comparison between CBD and fill depth in dependence of TBP, where the increasing TBP resulted in higher density values and therefore in lower required fill depths. According to the TBP in Equation (2) and DoE Results in Figure 7, this observation could be confirmed since impeller speed was shown as negative and throughput as positive model term on fill-depth values.

As already described, after a specific amount of revolutions, neither CBD nor FD values showed further changes with increasing TBP.

Figure $17 \mathrm{~b}$ shows the fill depth as a function of particle size $\left(\mathrm{d}_{10}\right)$. In general, smaller particle sizes are considered to decrease essential flowability, impacting a complete fill of the dies [47].

Regarding the die-filling process described by Xie and Puri [48], for powders with smaller particles, it is more challenging to lose entrained air due to cohesion during filling. Therefore, more volume and higher fill depths are required.. In this work, the correlation could be traced back again to lubrication, as described before, and not to cohesion $(-0.224$ $p=0.387)$.

Osorio and Muzzio [49] showed that higher powder compressibility values increase weight variability during capsule filling. Additionally, capsule weight decreased as powder compressibility increased. The same principle applies for die filling in this study, where higher powder compressibility led to higher fill depth values $(0.703 p<0.002)$ (Figure 17c). This observation may also be helpful if a capsule machine were used instead of a tablet press in continuous downstream processing.

\section{Ejection Force}

The ejection force is the required force to eject the tablet from the die and depends on the friction between the tablet and the die walls. Consequently, the reduction in ejection force is mainly influenced by the lubrication of the powder [50]. Usually, high ejection forces are accompanied by tableting problems and may cause damages to the tooling [51,52].

Regarding this dataset, the model-terms throughput and impeller speed shared the same deflections as for the fill depth (Figure 7); that means, it is indicated that a higher TBP results in a higher lubrication and lower ejection forces. However, although a strong correlation between ejection force and TBP was expected, only a correlation between ejection force and tablet-weight variability could be found $(0.787 p=0.0002)$. Nevertheless, a robust model regarding ejection force could be obtained by an MLR analysis $\left(Q^{2}=0.892\right.$ and $\left.\mathrm{R}^{2}=0.944\right)$. For further explanation regarding TBP and ejection force, see Supplementary Section G, "Ejection Force". 
(a)

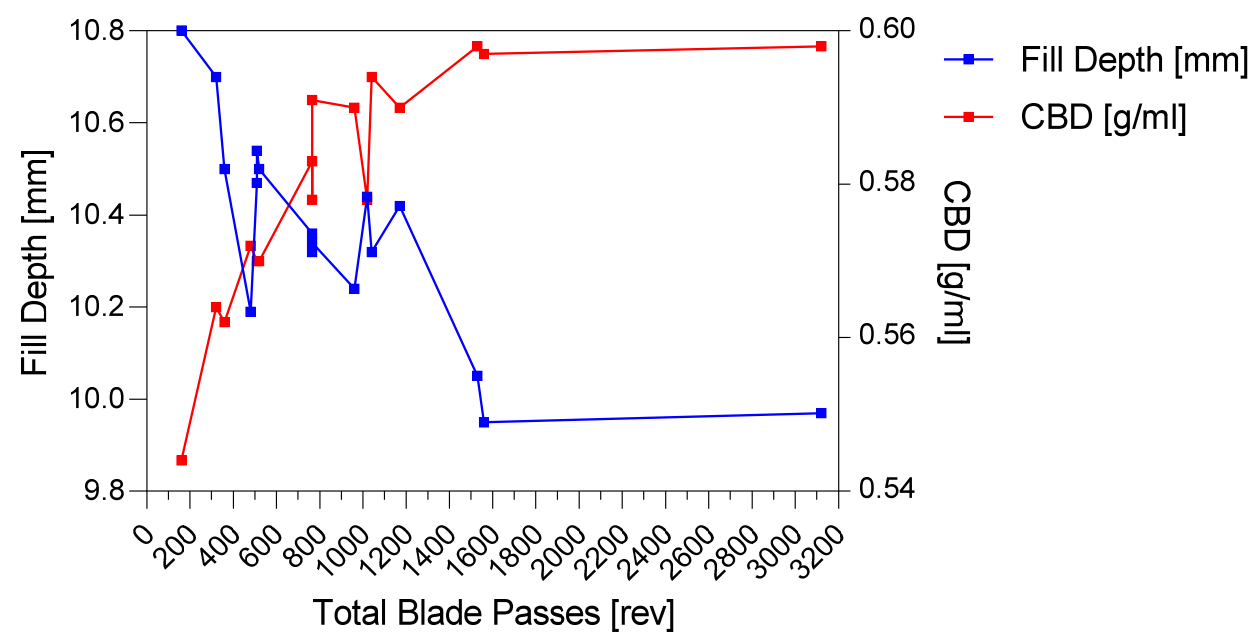

(b)

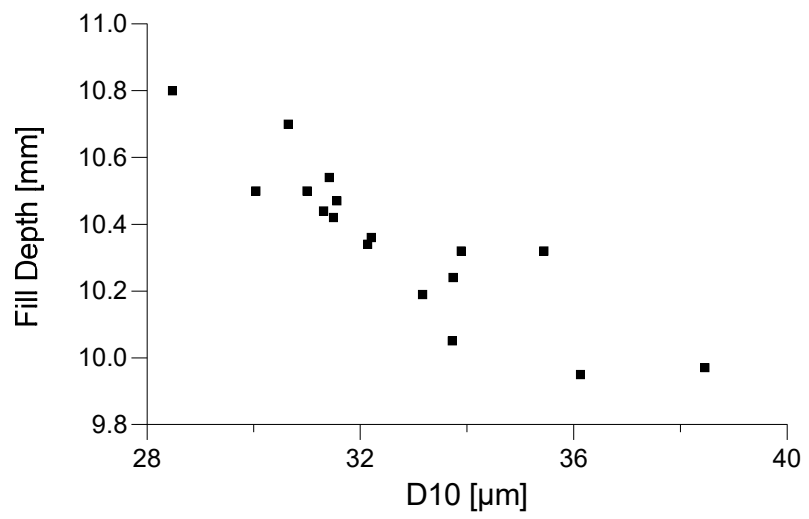

(c)

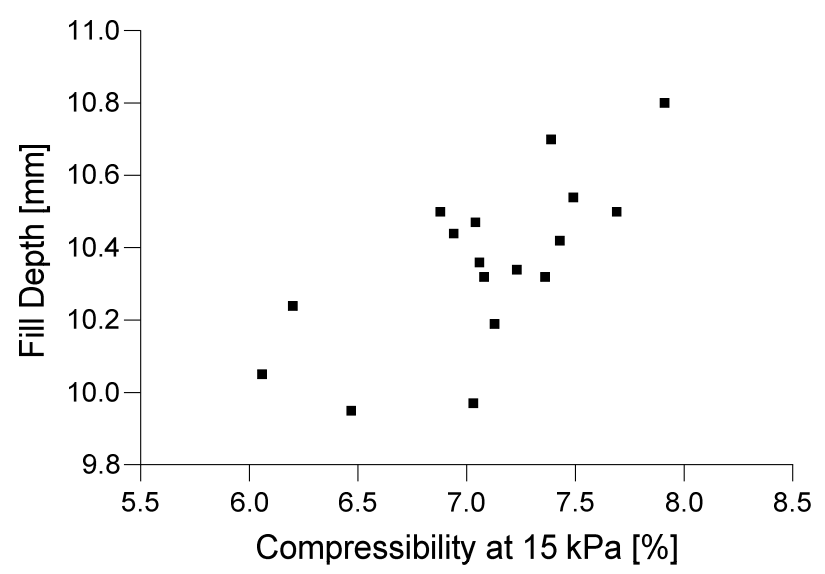

Figure 17. (a) Fill depth as function of total blade passes compared to bulk density. (b) Linearity between fill depth and $d_{10}$ values. (c) Impact of compressibility on fill depth.

\subsubsection{Tablet Properties}

Even if good models for TS, TW and TT could be found, only few correlations regarding TW and TT could be obtained (see paragraph "Ejection Force"). 
Tensile Strength

Figure 18 demonstrates the tensile strength (TS) as a function of TBP $(-0.704 p=0.002)$, wherein a higher TBP resulted in lower tensile strength at the same compression pressure $(275 \mathrm{MPa})$, due to increased lubrication efficiency. According to the DoE results in Figure 8, the significant model terms corresponded to the TBP Equation (2), where a higher throughput, lower HUM and lower impeller speed result in a lower TBP and, therefore, in higher tensile strengths of the tablet. If previous process states need to be optimized by adapting CMT parameters, a similar TBP should be maintained to ensure the correct TS.

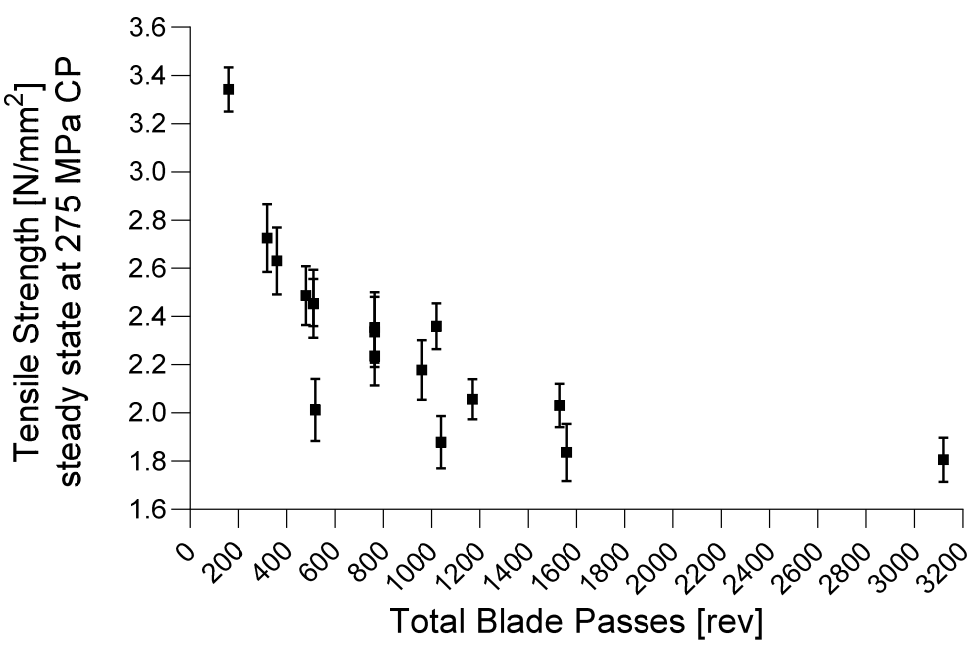

Figure 18. TS as a function of TBP at $275 \mathrm{MPa}$ compression pressure.

Again, after 1560 revolutions, a plateau was reached, and no further reduction in tensile strength could be noticed with the increasing TBP.

\section{Compression-Force Profile}

A compression-force profile was conducted by using 118, 157, 169, 236 and $275 \mathrm{MPa}$ compression pressure. During phase 16, no compression-force profile could be performed, because HUM increased from 0.8 to $\sim 1.1 \mathrm{~kg}$ and the exit valve opened up to $45 \mathrm{~mm}$, without any chance of decreasing. Thus, a consistent process flow could not be reached, and the correct setting of the FD and compression pressure was not possible.

Figure 19 includes the TS as a function of the corresponding compression pressure and TBP. Figure 19a demonstrates the profiles of each phase as a function of compression pressure, wherein the lowest TBP showed the highest values. Figure $19 \mathrm{~b}$ reflects the TS as a function of TBP, where higher compression pressure led to profiles with higher values. Table 10 shows the fit statistics regarding tensile strengths obtained during the compression-force profiles.

Table 10. Overview of fit statistics regarding tensile strengths obtained during compressionforce profiles.

\begin{tabular}{ccccc}
\hline Response Factor & Data Transformation & $\mathbf{Q}^{\mathbf{2}}$ & $\mathbf{R}^{\mathbf{2}}$ & Adjusted $\mathbf{R}^{\mathbf{2}}$ \\
\hline Tensile Strength at 118 MPa & Logarithmic & 0.905 & 0.958 & 0.942 \\
Tensile Strength at 157 MPa & Logarithmic & 0.877 & 0.963 & 0.944 \\
Tensile Strength at $169 \mathrm{MPa}$ & Logarithmic & 0.870 & 0.940 & 0.918 \\
Tensile Strength at 236 MPa & Logarithmic & 0.923 & 0.978 & 0.964 \\
Tensile Strength at 275 MPa & Logarithmic & 0.927 & 0.975 & 0.963 \\
\hline
\end{tabular}


(a)

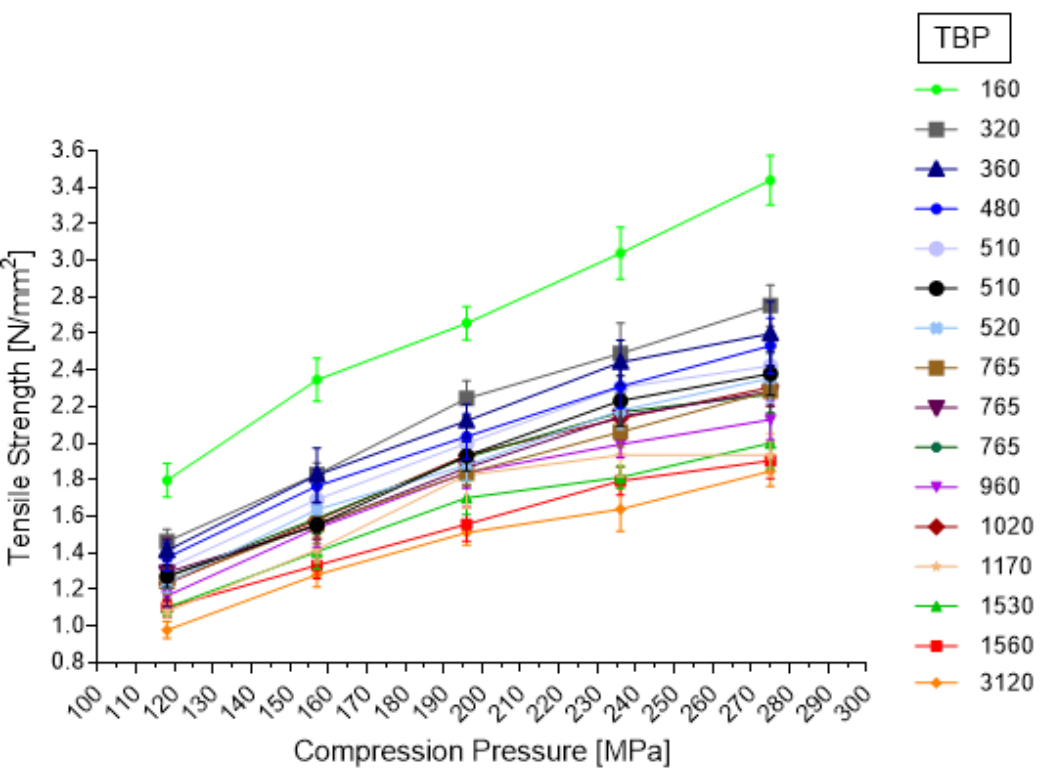

(b)

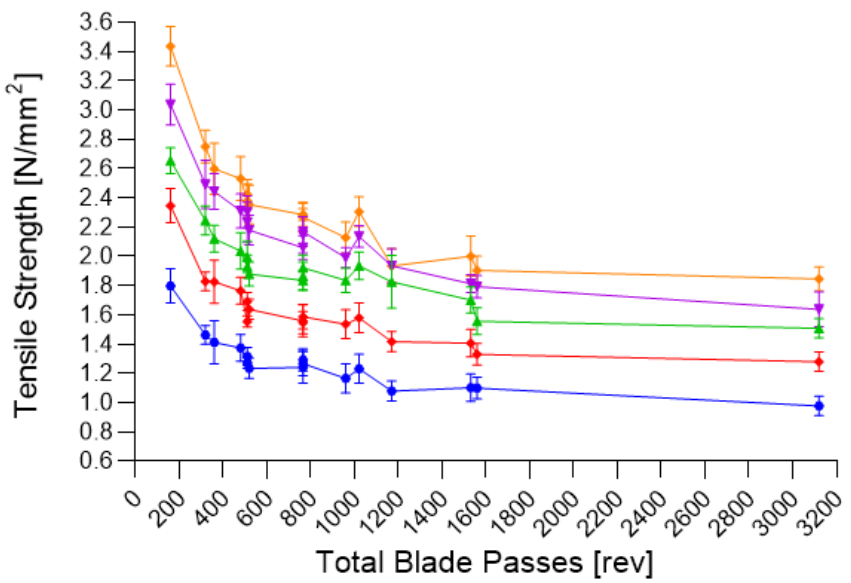

$-275 \mathrm{MPa}$
$-236 \mathrm{MPa}$
$-196 \mathrm{MPa}$
$-\quad 157 \mathrm{MPa}$
$-118 \mathrm{MPa}$

Figure 19. (a) Overview of all phases (TBP) regarding compression pressure and tensile strength. (b) Overview of all compression pressures and the corresponding tensile strength based on the lubrication (TBP).

\section{Sweet Spot}

By using MODDE, it is possible to detect a sweet spot where several criteria are met. For this paper, exit valve opening width $(1-5 \mathrm{~mm})$, blend potency SD $(0-3 \%)$, tensile strength (2-3 MPa) and tablet-weight variability $(0-2.5 \mathrm{mg})$ are considered critical parameters. In brackets, the favorable process values are shown. Figure 20 shows a visualization of a combination of input variables (throughput, hold-up mass and impeller speed) in which all criteria are met (light green). At an impeller speed of $650 \mathrm{rpm}$, no sweet spot could be achieved. With reducing impeller speeds, sweet spots at low throughputs are possible at 425 and $200 \mathrm{rpm}$. At $200 \mathrm{rpm}$, sweet spots could be achieved at low throughputs independently of HUM. Since it is preferred to run the process with higher throughputs, an optimal setting for this formulation can be observed at a combination of high throughputs and high HUM values at $200 \mathrm{rpm}$ impeller speed. 


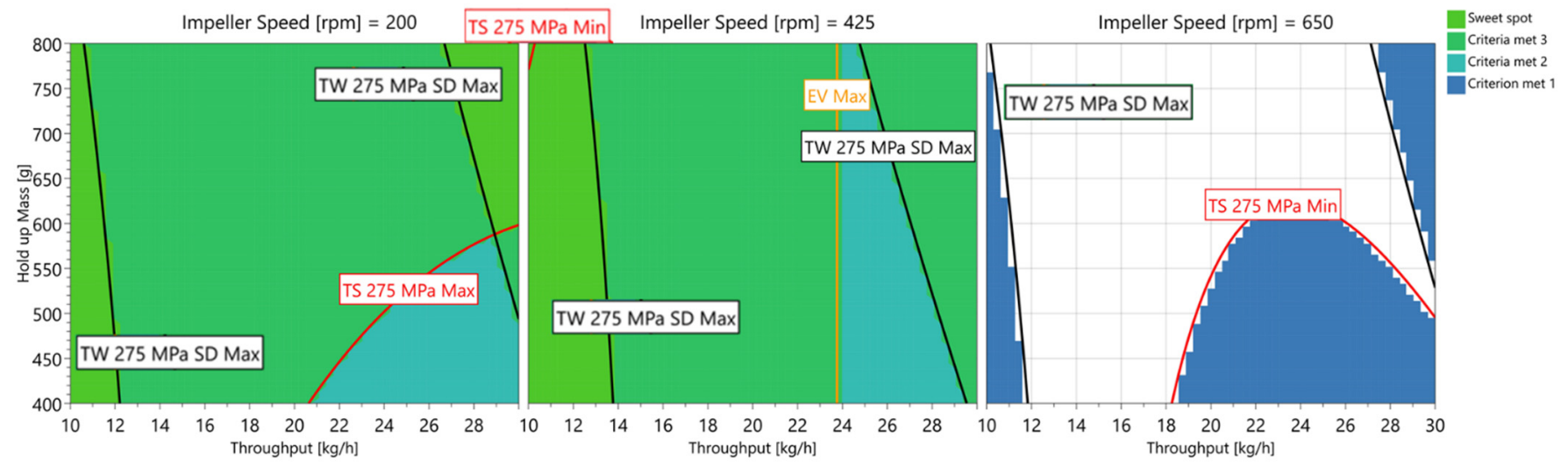

Figure 20. Sweet spot (light green) reveals the combination of the DoE input variables in which the criteria are met. The color of the borders indicate which criterion is not met anymore. Black borders = TW SD, red borders $=$ TS and orange boarders $=\mathrm{EV}$.

\section{Conclusions}

This paper showed the evaluation of the downstream process states based on throughput, hold-up mass and impeller speed in a continuous direct compression line, including a single blending step, in a vertical blender (CMT). For all settings in the performed DoE, the same composition and compounds were used, so that the initial material attributes and lubrication sensitivity remained constant.

In this study, the model terms of the process states based on the CMT parameters were evaluated by means of a MLR analysis. Corresponding fit statistics are shown in Table 11.

Table 11. Overview of the models obtained in this study.

\begin{tabular}{cccc}
\hline Responses & $\mathbf{Q}^{\mathbf{2}}$ & $\mathbf{R}^{\mathbf{2}}$ & Adjusted $\mathbf{R}^{\mathbf{2}}$ \\
\hline Exit valve opening width & 0.860 & 0.905 & 0.883 \\
Exit valve opening width SD & 0.822 & 0.933 & 0.893 \\
Torque of lower impeller & 0.851 & 0.916 & 0.896 \\
Torque of lower impeller SD & 0.882 & 0.949 & 0.933 \\
Conditioned bulk density & 0.735 & 0.850 & 0.816 \\
Flow rate index & 0.800 & 0.896 & 0.848 \\
Fill depth & 0.873 & 0.941 & 0.914 \\
Bottom main compression height & 0.774 & 0.928 & 0.885 \\
Ejection force & 0.892 & 0.944 & 0.931 \\
Tablet thickness & 0.718 & 0.953 & 0.917 \\
Tablet weight & 0.642 & 0.904 & 0.847 \\
Tensile strength & 0.907 & 0.976 & 0.958 \\
\hline
\end{tabular}

Furthermore, the connections between the parameters were evaluated. Regarding mixing parameters, it has been shown that the exit valve opening width and variability in exit valve, in hold-up mass, in torque and in blend potency are significantly correlated and can all be controlled mainly by impeller speed. If the improvement of these parameters is required, it needs to be considered that changes in impeller speed will also lead to changes in TBP.

With higher TBP, more shear is transmitted to the powder and more magnesium stearate will adhere to the remaining particles, leading to more lubrication and higher variation in material attributes. Hence, TBP significantly correlated with the blend's material attributes (density, $\mathrm{d}_{10}$ values and flow-rate index), the fill depth and the tensile strength of the tablets.

Target criteria (exit valve opening width $(1-5 \mathrm{~mm})$, blend potency SD $(0-3 \%)$, tensile strength (2-3 MPa) and tablet-weight variability $(0-2.5 \mathrm{mg})$ ) could generally be found at impeller speeds between 200 and $425 \mathrm{rpm}$ and at throughputs between 10 and $12 \mathrm{~kg} / \mathrm{h}$ 
independent of HUM. To run the process as fast as possible, high throughput, high HUM and $200 \mathrm{rpm}$ IMP are required to fulfill the target criteria and, therefore, represent the optimal setting for this formulation.

Supplementary Materials: The following supporting information can be downloaded at https: //www.mdpi.com/article/10.3390/pharmaceutics14020278/s1.

Author Contributions: Conceptualization, M.J.K. and K.G.W.; methodology, M.J.K. and K.G.W.; software, M.J.K.; formal analysis, M.J.K. and K.G.W.; investigation, M.J.K.; data curation, M.J.K.; writing—original draft preparation, M.J.K..; writing—review and editing, M.J.K., C.W. and K.G.W.; visualization, M.J.K.; supervision, K.G.W. and C.W.; project administration, K.G.W. and C.W. All authors have read and agreed to the published version of the manuscript.

Funding: This research was funded by Pfizer Manufacturing Deutschland GmbH.

Acknowledgments: We would like to thank the Pfizer MCT colleagues in Sandwich, UK, for supporting the powder analysis. We also want to acknowledge the work of the Pfizer R\&D colleagues in Groton, USA, and Sandwich, UK, who carefully read and reviewed the manuscript.

Conflicts of Interest: The authors declare no conflict of interest.

\section{Abbreviations}

API active pharmaceutical ingredient

$\mathrm{BCH}$ bottom main compression height

BFE basic flow energy

CBD conditioned bulk density

CMT continuous mixing technology

$\mathrm{CP} \quad$ compression pressure

DC direct compression

DoE design of experiment

EF ejection force

EV exit valve opening width

EV SD exit valve opening width standard deviation

FD fill depth

FRI flow rate index

HUM hold-up mass

IMP impeller speed

LiW loss in weight

MBM mass balance model

MCC microcrystalline cellulose

MgSt magnesium stearate

MLR multiple linear regression

MRT mean residence time

NIR near infrared

PCMM portable, continuous, modular, miniature

PID proportional-integral-derivative

PLS partial least square

PV process value

RTD residence-time distribution

SE specific energy

SI stability index

SNV standard normal variate

SD standard deviation

TBP total blade passes

THR throughput 


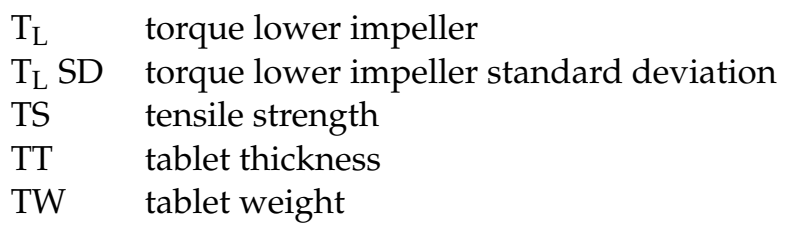

\section{References}

1. Blackwood, D.O.; Bonnassieux, A.; Cogoni, G. Continuous direct compression using portable continuous miniature modular \& manufacturing (PCM\&M). In Chemical Engineering in the Pharmaceutical Industry; John Wiley \& Sons, Ltd.: Hoboken, NJ, USA, 2019; pp. 547-560. [CrossRef]

2. Hsiao, W.-K.; Hörmann, T.R.; Toson, P.; Paudel, A.; Ghiotti, P.; Stauffer, F.; Bauer, F.; Lakio, S.; Behrend, O.; Maurer, R.; et al. Feeding of particle-based materials in continuous solid dosage manufacturing: A material science perspective. Drug Discov. Today 2020, 25, 800-806. [CrossRef] [PubMed]

3. Nowak, S.; K-Tron, C. Three Ways to Improve Continuous Loss-in-Weight Feeding Accuracy; CSC Publishing: St Paul, MN, USA, 2016.

4. Engisch, W.E.; Muzzio, F.J. Feedrate deviations caused by hopper refill of loss-in-weight feeders. Powder Technol. 2015, 283, 389-400. [CrossRef]

5. Gao, Y.; Muzzio, F.; Ierapetritou, M. Characterization of feeder effects on continuous solid mixing using fourier series analysis AIChE J. 2011, 57, 1144-1153. [CrossRef]

6. Hanson, J. Control of a system of loss-in-weight feeders for drug product continuous manufacturing. Powder Technol. 2018, 331, 236-243. [CrossRef]

7. Tahir, F.; Palmer, J.; Khoo, J.; Holman, J.; Yadav, I.K.; Reynolds, G.; Meehan, E.; Mitchell, A.; Bajwa, G. Development of feed factor prediction models for loss-in-weight powder feeders. Powder Technol. 2019, 364, 1025-1038. [CrossRef]

8. Toson, P.; Siegmann, E.; Trogrlic, M.; Kureck, H.; Khinast, J.; Jajcevic, D.; Doshi, P.; Blackwood, D.; Bonnassieux, A.; Daugherity, P.D.; et al. Detailed modeling and process design of an advanced continuous powder mixer. Int. J. Pharm. 2018, 552, 288-300. [CrossRef]

9. Engisch, W.E.; Muzzio, F.J. Loss-in-Weight Feeding Trials Case Study: Pharmaceutical Formulation. J. Pharm. Innov. 2015, 10, 56-75. [CrossRef]

10. Engisch, W.E.; Muzzio, F.J. Method for characterization of loss-in-weight feeder equipment. Powder Technol. 2012, 228, 395-403 [CrossRef]

11. Escotet-Espinoza, M.S.; Moghtadernejad, S.; Scicolone, J.; Wang, Y.; Pereira, G.; Schäfer, E.; Vigh, T.; Klingeleers, D.; Ierapetritou, M.; Muzzio, F.J. Using a material property library to find surrogate materials for pharmaceutical process development. Powder Technol. 2018, 339, 659-676. [CrossRef]

12. Hopkins, M. Loss in Weight Feeder Systems. Meas. Control. 2006, 39, 237-240. [CrossRef]

13. Wang, Y.; Li, T.; Muzzio, F.J.; Glasser, B.J. Predicting feeder performance based on material flow properties. Powder Technol. 2017, 308, 135-148. [CrossRef]

14. Gao, Y.; Vanarase, A.; Muzzio, F.; Ierapetritou, M. Characterizing continuous powder mixing using residence time distribution Chem. Eng. Sci. 2011, 66, 417-425. [CrossRef]

15. Marikh, K.; Berthiaux, H.; Gatumel, C.; Mizonov, V.; Barantseva, E. Influence of stirrer type on mixture homogeneity in continuous powder mixing: A model case and a pharmaceutical case. Chem. Eng. Res. Des. 2008, 86, 1027-1037. [CrossRef]

16. Lee, K.T.; Kimber, J.A.; Cogoni, G.; Brandon, J.K.; Wilsdon, D.; Verrier, H.M.; Grieb, S.; Blackwood, D.O.; Jain, A.C.; Doshi, P. Continuous Mixing Technology: Characterization of a Vertical Mixer Using Residence Time Distribution. J. Pharm. Sci. 2021, 110, 2694-2702. [CrossRef]

17. Mehrotra, A.; Llusa, M.; Faqih, A.; Levin, M.; Muzzio, F.J. Influence of shear intensity and total shear on properties of blends and tablets of lactose and cellulose lubricated with magnesium stearate. Int. J. Pharm. 2007, 336, 284-291. [CrossRef]

18. Swaminathan, V.; Kildsig, D.O. Effect of Magnesium Stearate on the Content Uniformity of Active Ingredient in Pharmaceutical Powder Mixtures. Aaps Pharmscitech 2002, 3, 27. [CrossRef]

19. Johansson, M.E. Granular magnesium stearate as a lubricant in tablet formulations. Int. J. Pharm. 1984, 21, 307-315. [CrossRef]

20. Ketterhagen, W.R.; Mullarney, M.P.; Kresevic, J.; Blackwood, D. Computational approaches to predict the effect of shear during processing of lubricated pharmaceutical blends. Powder Technol. 2018, 335, 427-439. [CrossRef]

21. Kushner, J. Incorporating Turbula mixers into a blending scale-up model for evaluating the effect of magnesium stearate on tablet tensile strength and bulk specific volume. Int. J. Pharm. 2012, 429, 1-11. [CrossRef]

22. Kushner, J.; Moore, F. Scale-up model describing the impact of lubrication on tablet tensile strength. Int. J. Pharm. 2010, 399, 19-30. [CrossRef]

23. Kushner, J.; Schlack, H. Commercial scale validation of a process scale-up model for lubricant blending of pharmaceutical powders. Int. J. Pharm. 2014, 475, 147-155. [CrossRef] [PubMed]

24. Portillo, P.M.; Ierapetritou, M.G.; Muzzio, F.J. Characterization of continuous convective powder mixing processes. Powder Technol. 2008, 182, 368-378. [CrossRef]

25. Wang, J.; Wen, H.; Desai, D. Lubrication in tablet formulations. Eur. J. Pharm. Biopharm. 2010, 75, 1-15. [CrossRef] [PubMed] 
26. Vanarase, A.U.; Alcalà, M.; Rozo, J.I.J.; Muzzio, F.J.; Romañach, R.J. Real-time monitoring of drug concentration in a continuous powder mixing process using NIR spectroscopy. Chem. Eng. Sci. 2010, 65, 5728-5733. [CrossRef]

27. De Leersnyder, F.; Peeters, E.; Djalabi, H.; Vanhoorne, V.; Van Snick, B.; Hong, K.; Hammond, S.; Liu, A.Y.; Ziemons, E.; Vervaet, C.; et al. Development and validation of an in-line NIR spectroscopic method for continuous blend potency determination in the feed frame of a tablet press. J. Pharm. Biomed. Anal. 2018, 151, 274-283. [CrossRef] [PubMed]

28. Peeters, M.; Peeters, E.; Van Hauwermeiren, D.; Cogoni, G.; Liu, Y.; De Beer, T. Determination and understanding of lead-lag between in-line NIR tablet press feed frame and off-line NIR tablet measurements. Int. J. Pharm. 2021, 611, 121328. [CrossRef]

29. Van Hauwermeiren, D.; Peeters, M.; Peeters, E.; Cogoni, G.; Yang, L.A.; De Beer, T. Development of a tablet press feed frame lead lag determination model using in-line and off-line NIR measurements. Int. J. Pharm. 2021, 612, 121284. [CrossRef]

30. Madian, A.; Leturia, M.; Ablitzer, C.; Matheron, P.; Bernard-Granger, G.; Saleh, K. Impact of fine particles on the rheological properties of uranium dioxide powders. Nucl. Eng. Technol. 2020, 52, 1714-1723. [CrossRef]

31. Freemann Technology. Instruction Documents: W7013 Stability and Variable Flow Rate; Freemann Technology: Tewkesbury, UK, 2007.

32. Freeman, R. Measuring the flow properties of consolidated, conditioned and aerated powders-A comparative study using a powder rheometer and a rotational shear cell. Powder Technol. 2007, 174, 25-33. [CrossRef]

33. Freemann Technology. Instruction Documents: W7012 Variable Flow Rate; Freemann Technology: Tewkesbury, UK, 2007.

34. Freemann Technology. Instruction Documents: W7030 Basic Flowability Energy; Freemann Technology: Tewkesbury, UK, 2007.

35. Freemann Technology. Instruction Documents: W7008 Compressibility; Freemann Technology: Tewkesbury, UK, 2007.

36. Freemann Technology. Instruction Documents: W7018 Shear Cell; Freemann Technology: Tewkesbury, UK, 2007.

37. Freemann Technology. Instruction Documents: W7050 1ml Shear Cell; Freemann Technology: Tewkesbury, UK, 2007.

38. Freeman, R.E.; Cooke, J.R.; Schneider, L.C.R. Measuring shear properties and normal stresses generated within a rotational shear cell for consolidated and non-consolidated powders. Powder Technol. 2009, 190, 65-69. [CrossRef]

39. Wang, Y.; Koynov, S.; Glasser, B.J.; Muzzio, F.J. A method to analyze shear cell data of powders measured under different initial consolidation stresses. Powder Technol. 2016, 294, 105-112. [CrossRef]

40. Peeters, E. Investigation of the Tableting Process in Continuous Production: Influence of Feeding and Extended Dwell Time during Compression on Dependent Process Variables and Tablet Properties; Ghent Univeristy: Ghent, Belgium, 2014.

41. Pitt, K.G.; Newton, J.M.; Stanley, P. Tensile fracture of doubly-convex cylindrical discs under diametral loading. J. Mater. Sci. 1988, 23, 2723-2728. [CrossRef]

42. Mukaka, M.M. Statistics corner: A guide to appropriate use of correlation coefficient in medical research. Malawi Med. J. 2012, 24, 69-71. [PubMed]

43. Knight, P.; Seville, J.; Wellm, A.; Instone, T. Prediction of impeller torque in high shear powder mixers. Chem. Eng. Sci. 2001, 56, 4457-4471. [CrossRef]

44. Moghtadernejad, S.; Escotet-Espinoza, M.S.; Oka, S.; Singh, R.; Liu, Z.; Román-Ospino, A.D.; Li, T.; Razavi, S.; Panikar, S.; Scicolone, J.; et al. A Training on: Continuous Manufacturing (Direct Compaction) of Solid Dose Pharmaceutical Products. J. Pharm. Innov. 2018, 13, 155-187. [CrossRef]

45. Morin, G.; Briens, L. The Effect of Lubricants on Powder Flowability for Pharmaceutical Application. AAPS PharmSciTech 2013, 14, 1158-1168. [CrossRef]

46. Razavi, S.M.; Gonzalez, M.; Cuitiño, A.M. Quantification of lubrication and particle size distribution effects on tensile strength and stiffness of tablets. Powder Technol. 2018, 336, 360-374. [CrossRef]

47. Goh, H.P.; Heng, P.W.S.; Liew, C.V. Comparative evaluation of powder flow parameters with reference to particle size and shape Int. J. Pharm. 2018, 547, 133-141. [CrossRef]

48. Xie, X.; Puri, V.M. Uniformity of Powder Die Filling Using a Feed Shoe: A Review. Part. Sci. Technol. 2006, 24, 411-426. [CrossRef]

49. Osorio, J.G.; Muzzio, F.J. Effects of powder flow properties on capsule filling weight uniformity. Drug Dev. Ind. Pharm. 2012, 39, 1464-1475. [CrossRef]

50. Uzondu, B.; Leung, L.Y.; Mao, C.; Yang, C.-Y. A mechanistic study on tablet ejection force and its sensitivity to lubrication for pharmaceutical powders. Int. J. Pharm. 2018, 543, 234-244. [CrossRef] [PubMed]

51. Anuar, M.; Briscoe, B. The elastic relaxation of starch tablets during ejection. Powder Technol. 2009, 195, 96-104. [CrossRef]

52. Dun, J.; Osei-Yeboah, F.; Boulas, P.; Lin, Y.; Sun, C.C. A systematic evaluation of poloxamers as tablet lubricants. Int. J. Pharm. 2020, 576, 118994. [CrossRef] [PubMed] 